\title{
Ultrasonic Examination of Double-Shell Tank 241-AW-101
} Examination Completed February 2009

\begin{abstract}
AF Pardini
DR Weier

KK Anderson
\end{abstract}

March 2009

\section{Pacific Northwest}

NATIONAL LABORATORY

Proudly Operated by Battelle Since 1965 


\title{
DISCLAIMER
}

This report was prepared as an account of work sponsored by an agency of the United States Government. Neither the United States Government nor any agency thereof, nor Battelle Memorial Institute, nor any of their employees, makes any warranty, express or implied, or assumes any legal liability or responsibility for the accuracy, completeness, or usefulness of any information, apparatus, product, or process disclosed, or represents that its use would not infringe privately owned rights. Reference herein to any specific commercial product, process, or service by trade name, trademark, manufacturer, or otherwise does not necessarily constitute or imply its endorsement, recommendation, or favoring by the United States Government or any agency thereof, or Battelle Memorial Institute. The views and opinions of authors expressed herein do not necessarily state or reflect those of the United States Government or any agency thereof.

\author{
PACIFIC NORTHWEST NATIONAL LABORATORY \\ operated by \\ BATTELLE \\ for the \\ UNITED STATES DEPARTMENT OF ENERGY \\ under Contract DE-AC05-76RL01830
}

Printed in the United States of America
Available to DOE and DOE contractors from the Office of Scientific and Technical Information,
P.O. Box 62, Oak Ridge, TN 37831-0062;
ph: (865) 576-8401
fax: $(865)$ 576-5728
email: reports@adonis.osti.gov

\begin{abstract}
Available to the public from the National Technical Information Service, U.S. Department of Commerce, 5285 Port Royal Rd., Springfield, VA 22161 ph: (800) 553-6847 fax: $(703) 605-6900$ email: orders@ntis.fedworld.gov online ordering: http://www.ntis.gov/ordering.htm
\end{abstract}

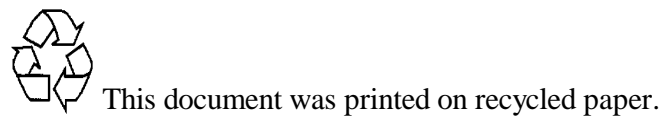




\title{
Ultrasonic Examination of Double-Shell Tank 241-AW-101 Examination Completed February 2009
}

\author{
AF Pardini \\ DR Weier \\ KK Anderson
}

March 2009

Prepared for

the U.S. Department of Energy

under Contract DE-AC05-76RL01830

Pacific Northwest National Laboratory

Richland, Washington 99352 


\section{Summary}

AREVA Federal Services LLC (AFS), under a contract from Washington River Protection Solutions (WRPS), has performed an ultrasonic examination of selected portions of Double-Shell Tank 241-AW101. The purpose of this examination was to provide information that could be used to evaluate the integrity of the wall of the primary tank. The requirements for the ultrasonic examination of Tank 241AW-101 were to detect, characterize (identify, size, and locate), and record measurements made of any wall thinning, pitting, or cracks that might be present in the wall of the primary tank. Any measurements that exceed the requirements set forth in the Engineering Task Plan (ETP), RPP-Plan-38332 (Castleberry 2008) and summarized on page 1 of this document, are to be reported to WRPS and the Pacific Northwest National Laboratory (PNNL) for further evaluation. Under the contract with WRPS, all data is to be recorded on electronic media and paper copies of all measurements are provided to PNNL for third-party evaluation. PNNL is responsible for preparing a report(s) that describes the results of the AFS ultrasonic examinations.

\section{Examination Results}

The results of the examination of Tank 241-AW-101 have been evaluated by PNNL personnel. The ultrasonic examination consisted of two vertical 15-in.-wide scan paths over the entire height of the tank and the heat-affected zone (HAZ) of four vertical welds and one horizontal weld and the liquid/air interface on Plate \#1 and the upper haunch (dome) from Riser 28. The examination also included two vertical 15-in.-wide scan paths over the entire height of the tank from Riser 29. The examination was performed to detect any wall thinning, pitting, or cracking in the primary tank wall.

\section{Primary Tank Wall Vertical Scan Paths}

Two 15-in.-wide vertical scan paths were performed on Plates \#1, \#2, \#3, \#4, and \#5 from Riser 28. The plates were examined for wall thinning, pitting, and cracks oriented vertically on the primary tank wall. There were no areas of wall thinning that exceeded the reportable level of $10 \%$ of the nominal thickness. No pitting or vertical crack-like indications were detected in Plates \#1, \#2, \#3, \#4, or \#5.

Two 15-in.-wide vertical scan paths were performed on Plates \#1, \#2, \#3, \#4, and \#5 from Riser 29. The plates were examined for wall thinning, pitting, and cracks oriented vertically on the primary tank wall. Plate \#4 results indicated one area that exceeded the minimum thinning reportable level of $10 \%$ of the nominal thickness. However, the indication was evaluated by the ultrasonic UT Level III and was considered pit-like and therefore does not exceed the reportable pitting level of $25 \%$ of the nominal thickness. No pitting indications were detected in Plates \#1, \#2, \#3, or \#5. There were no areas of wall thinning that exceeded the reportable level of $10 \%$ of the nominal thickness. No vertical crack-like indications were detected in Plates \#1, \#2, \#3, \#4, or \#5. 


\section{Primary Tank Wall Weld Scan Paths}

The HAZ of vertical welds in Plates \#2, \#3, \#4, and \#5 from Riser 28 were examined for wall thinning, pitting, and cracks oriented either perpendicular or parallel to the weld. There were no areas of wall thinning that exceeded the reportable level of $10 \%$ of the nominal thickness. No pitting or cracklike indications were detected in the weld HAZ areas in Plates \#2, \#3, \#4, and \#5.

The HAZ of the horizontal weld between Plate \#5 and the tank knuckle from Riser 28 was examined for wall thinning, pitting and cracks oriented either perpendicular or parallel to the weld. There were no areas of wall thinning that exceeded the reportable level of $10 \%$ of the nominal thickness. No pitting or crack-like indications were detected in the weld HAZ areas on Plate \#5 side or on the knuckle side of the horizontal weld.

\section{Primary Tank Wall Liquid/Air Interface Horizontal Scan Paths}

Two horizontal scan paths were performed in the liquid/air interface region on Plate \#1 and the upper haunch (dome) of the primary tank. The areas were examined for wall thinning on the primary tank wall. There was one area on the upper haunch (dome) with minimum thickness of 0.335 -in. that exceeded the reportable level of $10 \%$ of the nominal thickness.

\section{Ultrasonic Data Statistical Analysis}

Extreme Value: Extreme value measured wall thickness losses were estimated within plate/riser combinations so results could potentially be evaluated across plate courses with differing nominal thickness. Since current remaining wall thickness typically still often exceeds drawing nominal, thereby generating negative losses, UT image maximum values were used instead to determine estimated nominal wall thickness per plate/riser combination. These thicknesses tended to run from drawing nominal up to about to nearly 0.040 -in. greater. They in turn were used with each UT image minimum value to determine estimated wall thickness loss per image. These losses which were then combined for a plate course over two risers, two paths per riser.

Tank 241- AW-101is among the first tanks to have UT image maximum values available from the original older inspection. Since only one riser was used, the maxima were not used here for one riser, and not the other, since it would introduce a systematic difference between risers. However, when the first older inspections are encountered that do have two risers used, then an issue will be raised on whether the best estimates of the original plate wall thicknesses are from the old or new UT image maxima.

Three-parameter Weibull distributions were fit to plate course combinations of Plates \#2 and \#4 and Plates \#1, \#3, and \#5 since somewhat greater losses were indicated in Plates \#2 and \#4. Plate \#4 contained two large outlying loss values that have large impact on results. For this reason results were given for Plates \#2 and \#4 combined, and for all plates combined, both with and without the two outlying values to show their impact. 
For Plates \#1, \#3, and \#5 combined, an estimated worst case extreme value loss around the tank is 0.064-in. This loss has $95 \%$ statistical confidence bound of 0.069 -in. Note these losses are relative to estimated maximum plate thicknesses meant to approximate original wall thicknesses and are thereby greater than drawing nominal. This generates an estimated worst case measured wall thickness loss since both measurement variability and actual wall thickness variability are included in the estimation process.

The corresponding Plate \#2 and \#4 estimate/bound values are 0.095-in./ 0.107-in. when the two outlying values are included. Without the outliers, the values are instead 0.074-in./ 0.081-in. The outlying values have considerable impact, and they apparently come from some other physical condition that is not generating the smaller values. Fitting a statistical distribution across both the smaller values and the two outliers is therefore probably inappropriate. Instead the Plate \#2 and \#4 results without the outliers are probably the best statistical estimates of extreme values. But then it should be understood that around the circumference of the tank there are likely some other more extreme cases caused by whatever physical phenomenon caused these two outlying values. We certainly cannot fit a separate distribution to only two points to make some kind of worse case prediction for these more extreme cases.

Riser Differences: Two inspections paths were completed down each of Risers 28 and 29. The use of two risers was based on initial studies of the first multi-riser-inspected Tank 241-AY-101 (in 2005). In that case, statistically significant riser differences were indicated, so it was determined that either multiple risers should be used in subsequent UT tank inspections, or if only a single riser were used, an extra uncertainty factor should be incorporated to account for such riser variability.

However, the resulting 2007, 2008, and now 2009 two-riser UT inspections of several tanks have tended to indicate that riser differences are not nearly as significant as originally thought. Discussion of inspection reduction to three or four paths down a single riser has been held, but for now the preference is to maintain the two-riser inspections. For the current Tank 241-AW-101 UT inspection, only modest differences between risers are indicated.

Old versus New Inspection Comparison: Approximately the same Tank 241-AW-101 wall areas were inspected both in the previous 2001 inspection and in the current 2009 inspection. This was the case for two inspection paths in Riser 28, so about 70 pairs of old and new UT image results could be compared. One elevation in path 1 was omitted since considerable wall thinning was indicated in the older inspection at that elevation, but it could not be found again in the new inspection after considerable effort. Since this one location generated a very large wall thickness gain from the old to new inspection, it was omitted from summary analyses.

For Tank 241-AW-101measured wall thickness reductions from the old to new are less than have been observed for most tanks that have been twice inspected. They ran about 0.007 -in., that is, less than 0.001-in per year. 


\section{Contents}

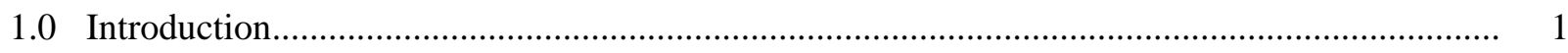

2.0 Qualified Personnel, Procedures, and Equipment....................................................... 2

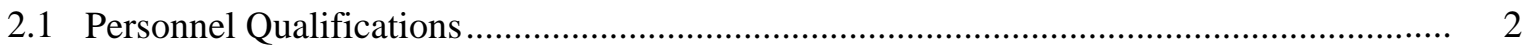

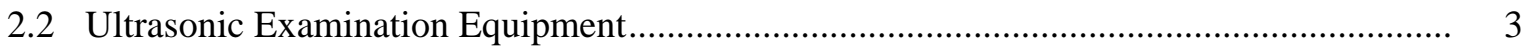

2.3 Ultrasonic Examination Procedure ………................................................................. 3

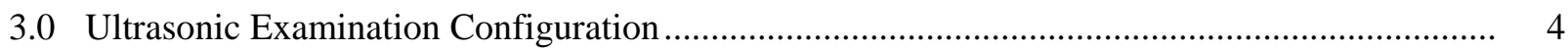

3.1 Primary Tank Wall Transducer Configuration .......................................................... 4

3.2 Weld Zone Transducer Configuration ........................................................................... 5

4.0 Ultrasonic Examination Location ............................................................................... 7

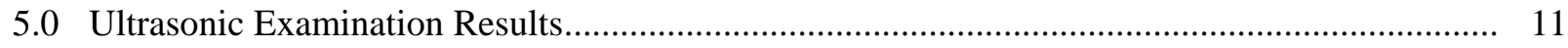

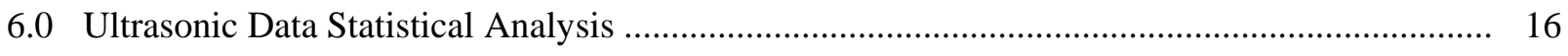

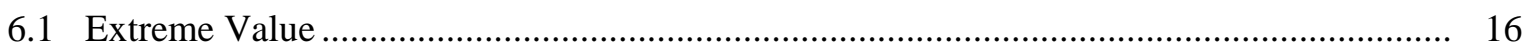

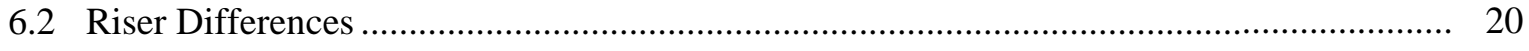

6.3 Comparison between 2001 and 2009 Data ................................................................. 22

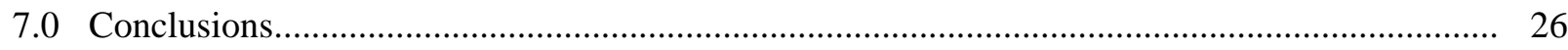

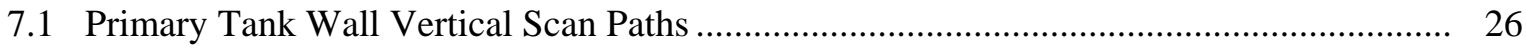

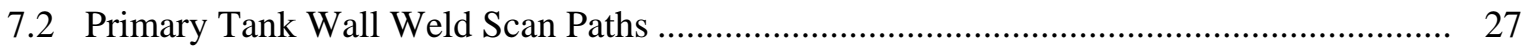

7.3 Primary Tank Wall Liquid/Air Interface Horizontal Scan Paths ...................................... 27

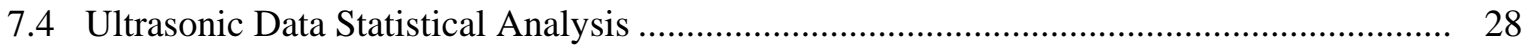

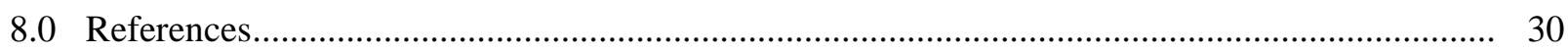




\section{Figures}

3.1 Transducer Configuration for Examining the Primary Tank Wall..................................... 4

3.2 Transducer Configurations for Examination of Weld Zone in the Primary Tank Wall ........... 5

3.3 Views of the Weld Zone to be Ultrasonically Examined in the Primary Tank Wall .............. 6

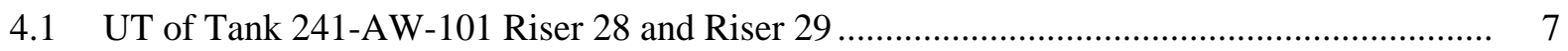

4.2 Sketch of Scan Paths on Tank 241-AW-101 Primary Tank from Riser 28.......................... 9

4.3 Sketch of Scan Paths on Tank 241-AW-101 Primary Tank from Riser 29.......................... 10

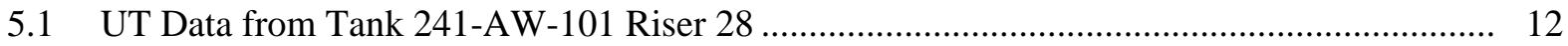

5.2 UT Data from Tank 241-AW-101 Riser 28 cont. .......................................................... 13

5.3 UT Data from Tank 241-AW-101 Riser 29.................................................................. 14

5.4 UT Data from Tank 241-AW-101 Riser 29 cont. ........................................................... 15

6.1 Estimated Nominal Thickness from UT Maxima ........................................................... 17

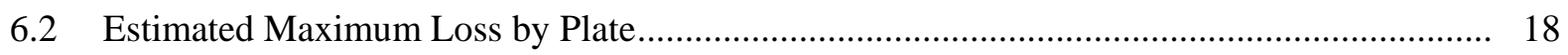

6.3 Weibull Distribution Fits to UT Maximum Wall Thickness Loss for Plate Course

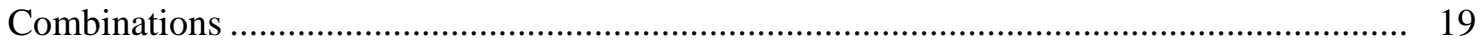

6.4 Tank 241-AW-101 Wall Thickness Extreme Value Loss Estimates and Bounds ................. 20

6.5 Riser 28 Minus Riser 29 Differences in UT Measured Wall Thickness .............................. 21

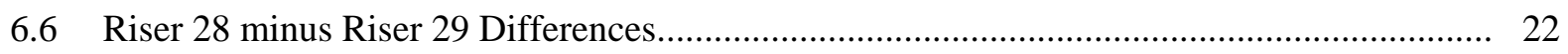

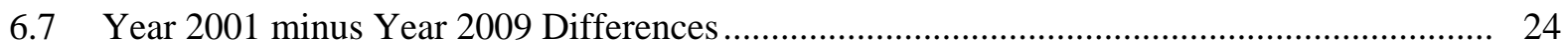

6.8 Year 2001 versus Year 2009 Measurement Paths.............................................................. 25 


\subsection{Introduction}

AREVA Federal Services LLC (AFS), under a contract from Washington River Protection Solutions (WRPS), has performed an ultrasonic examination (UT) of selected portions of Double-Shell Tank (DST) 241-AW-101. The purpose of this examination was to provide information that could be used to evaluate the integrity of the DST. The requirements for the UT of Tank 241-AW-101 were to detect, characterize (identify, size, and locate), and record measurements made of any wall thinning, pitting, or cracks that might be present in the wall of the primary tank. Any measurements that exceed the requirements set forth in the Engineering Task Plan (ETP), RPP-Plan-38332 (Castleberry 2008), are to be reported to WRPS and the Pacific Northwest National Laboratory (PNNL) for further evaluation. Specific measurements that are reported include the following:

- Wall thinning that exceeds $10 \%$ of the nominal thickness of the plate.

- Pits with depths that exceed $25 \%$ of the nominal plate thickness.

- Stress-corrosion cracks that exceed 0.10 in. (through-wall) and are detected in the inner wall of the tank, HAZ of welds, or in the tank knuckle.

The accuracy requirements for ultrasonic measurements for the different types of defects are as follows:

- Wall thinning - measure thickness within \pm 0.020 in.

- Pits - size depths within \pm 0.050 in.

- Cracks - size the depth of cracks on the inner wall surfaces within \pm 0.1 in.

- Location - locate all reportable indications within \pm 1.0 in.

Under the contract with WRPS, all data is to be recorded on electronic media and paper copies of all measurements are provided to PNNL for third-party evaluation. PNNL is responsible for preparing a report(s) that describes the results of the AFS UT. 


\subsection{Qualified Personnel, Procedures, and Equipment}

Under contract from WRPS, qualification of personnel participating in the DST inspection program, the UT equipment (instrument and mechanical scanning fixture), and the UT procedure that will be used in the examination of the current DST is required. Personnel participating in the examinations are to be certified in accordance with American Society for Nondestructive Testing (ASNT) Recommended Practice SNT-TC-1A, 1996 Edition (with 1998 Addenda), and associated documentation is to be provided. The capability of the UT system is to be validated through a performance demonstration test (PDT) on a mock-up simulating the actual DST. The current procedure for the UT is to be based on requirements listed in the American Society for Mechanical Engineers (ASME), Boiler and Pressure Vessel Code Section V, Article 4, 2001 Edition, Ultrasonic Examination Methods for Inservice Inspection.

\subsection{Personnel Qualifications}

The following individuals were qualified and certified to perform UT of the Hanford DST 241-AW101:

- Mr. Wesley Nelson, ASNT Level III (\#LM-1874) in UT, has been identified as AFS's UT Level III authority for this project. Mr. Nelson has been certified by AFS as a UT Level III in accordance with AFS procedure RCD-NE-PRC-AD2, latest revision which conforms to the requirements of ASNT SNT-TC-1A, 1996 (with 1998 Addenda). Further documentation has been provided to establish his qualifications (Pardini 2000).

- Mr. James B. Elder, ASNT Level III (\#JM-1891) in UT, has been contracted by AFS to provide data analysis of all DST UT data for this tank. Mr. Elder has been certified by JBNDT as a UT Level III in accordance with JBNDT written practice JBNDT-WP-1, latest revision. Further documentation has been provided to establish his qualifications (Posakony and Pardini 1998).

- Mr. William D. Purdy, AFS UT Level II limited (for P-Scan data acquisition only). Mr. Purdy has been certified in accordance with AFS procedure RCD-NE-PRC-AD2, latest revision. Further documentation has been provided to establish his qualifications (Posakony 2001).

- Mr. Jeffery S. Pintler, AFS UT Level II limited (for P-Scan data acquisition only). Mr. Pintler has been certified in accordance with AFS procedure RCD-NE-PRC-AD2, latest revision. Further documentation has been provided to establish his qualifications (Pardini 2006).

- Ms. Laura A. Sepich, AFS UT Level II limited (for P-Scan data acquisition only). Ms. Sepich has been certified in accordance with AFS procedure RCD-NE-PRC-AD2, latest revision. Further documentation has been provided to establish her qualifications (Pardini 2009). 


\subsection{Ultrasonic Examination Equipment}

WRPS has provided the UT equipment for the examination of Tank 241-AW-101. This equipment consists of a Force Technology P-Scan ultrasonic test instrument and Force Technology AWS-5D and AGS-2 remote-controlled, magnetic-wheel crawlers for examining the primary tank wall. Ultrasonic transducers used for the examinations are commercially available. The P-Scan ultrasonic system has been qualified through a PDT administered by PNNL (Posakony and Pardini 1998).

\subsection{Ultrasonic Examination Procedure}

AFS has provided the UT procedure for the examination of Tank 241-AW-101. This procedure, RCD-NE-INS-UT1.3, Revision 00, outlines the type of UT and mechanical equipment that are to be used as well as the types of transducers. Both straight-beam and angle-beam transducers are used for the examination of the primary tank wall. The examination procedures include full documentation on methods for calibration, examination, and reporting. Hard copies of the T-Scan (thickness) and P-Scan (projection or angle beam) views of all areas scanned are made available for analysis. The UT procedure requires the use of specific UT transducers for the different examinations. A calibration performed before and after the examinations identifies the specific transducers used and the sensitivity adjustments needed to perform the inspection. The AFS UT procedure has been qualified through a PDT (Posakony and Pardini 1998). 


\subsection{Ultrasonic Examination Configuration}

AFS is required to inspect selected portions of the DSTs which may include the primary and secondary tank walls, the HAZ of the primary tank vertical and horizontal welds, and the tank knuckle and bottoms. The P-Scan system has been configured to perform these examinations and has been performance tested. The examination of Tank 241-AW-101 included UT of the primary tank wall and the HAZ of selected welds in the primary tank wall.

\subsection{Primary Tank Wall Transducer Configuration}

Figure 3.1 provides an example of the scanning configuration generally used during an examination of the primary tank wall. However, other configurations can be used at the discretion of the AFS UT Level III (i.e., 45-degree transducers can be removed for simple wall thickness measurements). The functional diagram in Figure 3.1 shows one straight-beam and two angle-beam transducers ganged together for examining the primary tank wall. The straight beam is designed to detect and record wall thinning and pits, and the angle beams are designed to detect and record any cracking that may be present. These transducers are attached to the scanning bridge and they all move together. Information is captured every 0.035 -in. (or as set by the UT inspector) as the assembly is scanned across a line. At the end of each scan line the fixture is indexed 0.035-in. (or as set by the UT inspector) and the scan is repeated. The mechanical scanning fixture is designed to scan a maximum of approximately 15 -in. and then index for the next scan. The hard copy provides a permanent record that is used for the subsequent analysis.

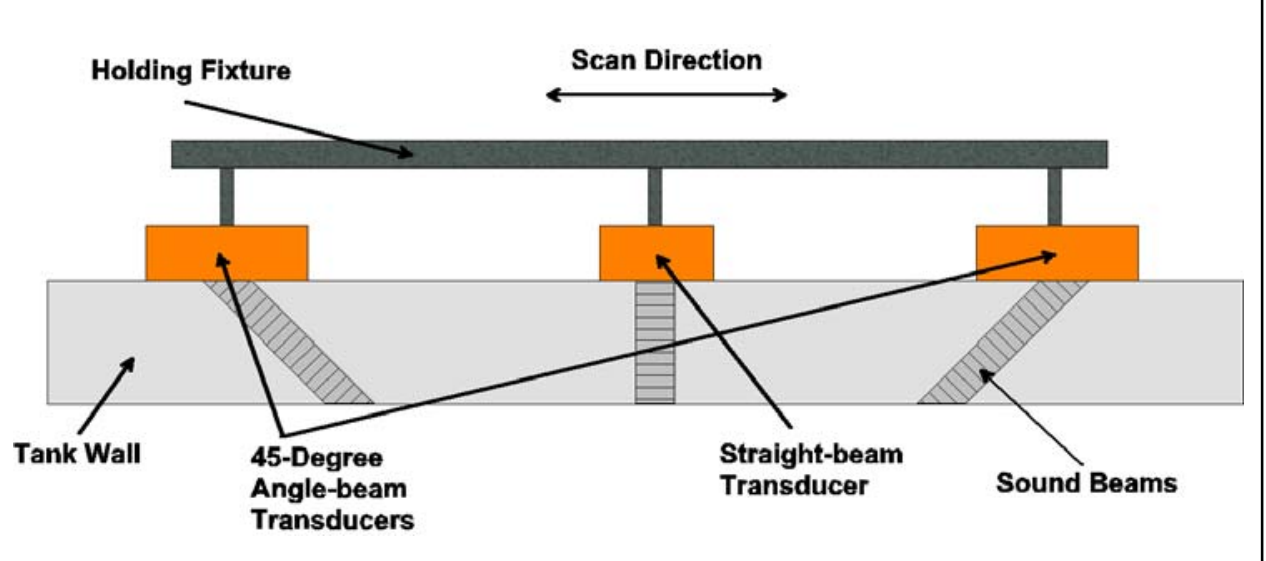

Transducer Specifications:

Angle-Beam

Type: MWB-45 04E

Frequency: $4 \mathrm{MHz}$

Size: $8 \times 9 \mathrm{~mm}$

Manufacturer: GE

Straight-Beam

Type: MSEB 5B

Frequency: $5 \mathrm{MHz}$

Size: Dual - 9 X $2 \mathrm{~mm}$

Manufacturer: GE

Figure 3.1. Transducer Configuration for Examining the Primary Tank Wall 


\subsection{Weld Zone Transducer Configuration}

Figure 3.2 is a functional sketch that shows the configurations for examination of the weld zone. The area of interest (HAZ of the weld) is shown as lying adjacent to the weld. Both cracks and pitting may occur in this region. The "A" portion of this sketch shows the 60-degree angle-beam transducers used for detecting cracks parallel to the weld. The straight-beam transducers in this sketch are used for detecting and recording any pitting or wall thinning that may be present. All transducers are ganged together. The scanning distance traveled is limited to a total of approximately 5.0-in. The sketch titled "B" shows the arrangement for detecting cracks that may lie perpendicular to the weld. Four 45-degree, angle-beam transducers are used for this inspection. Again the transducers are ganged together but the scan is limited to a total of approximately 4.0-in. The weld zone requirements are shown in Figure 3.3. The scan protocol, data capture, and index parameters are the same for examining other weld areas in the tank.

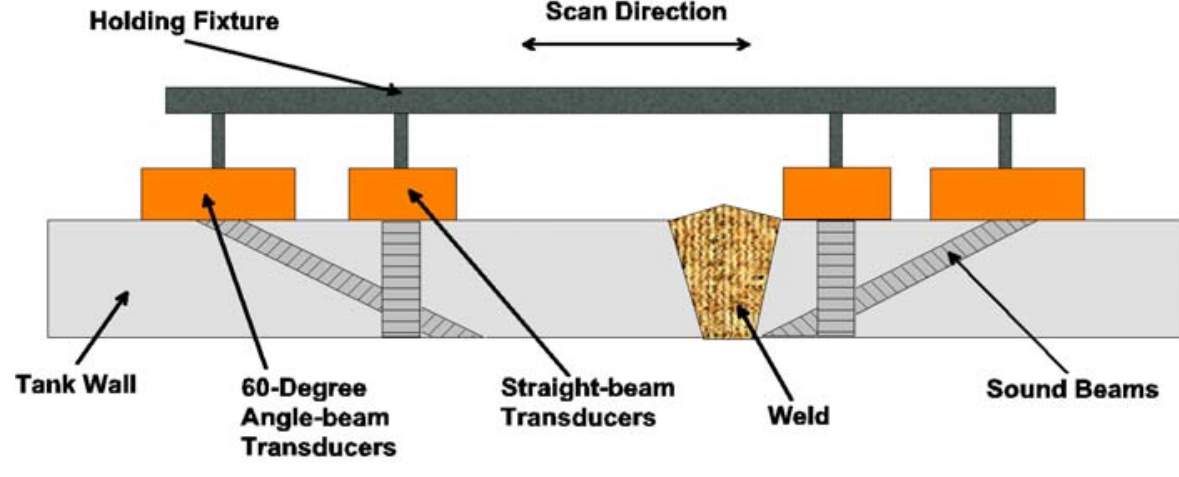

A. Configuration for pitting and cracks parallel to weld

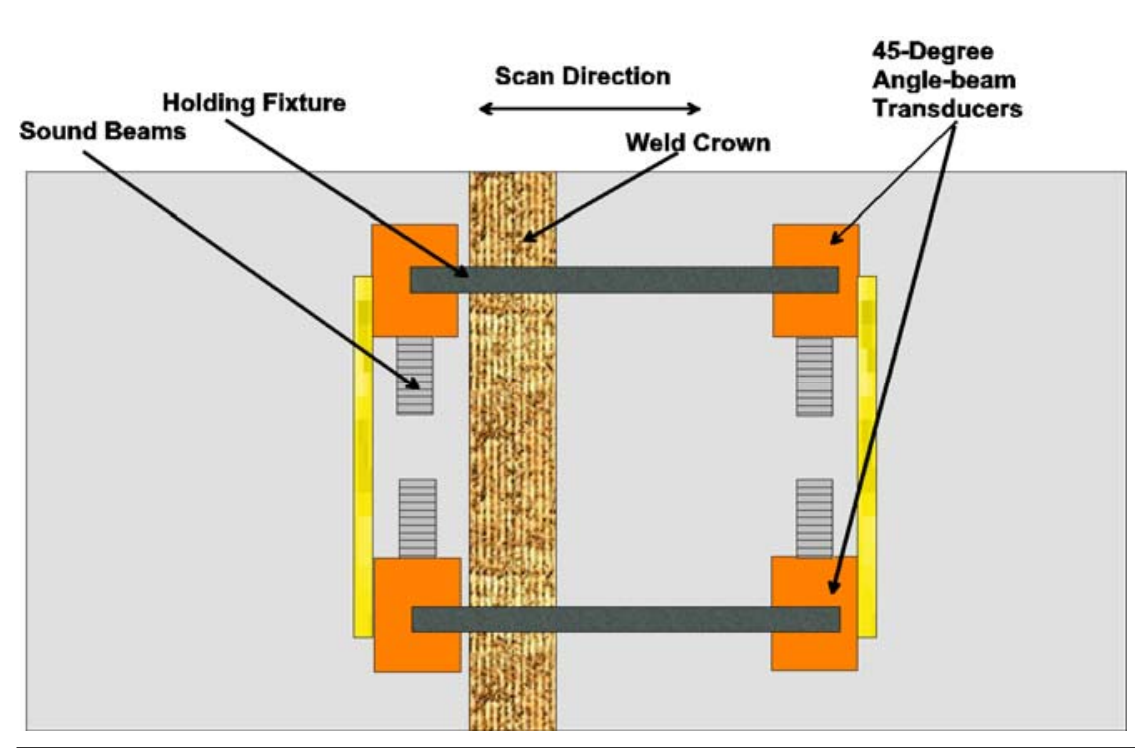

B. Configuration for cracks perpendicular to weld

\section{Transducer Specifications:}

Angle-Beam

Type: MWB-60 04E

Frequency: $4 \mathrm{MHz}$

Size: $8 \times 9 \mathrm{~mm}$

Manufacturer: GE

Straight-Beam

Type: MSEB 5B

Frequency: $5 \mathrm{MHz}$

Size: Dual - 9 X 2 mm

Manufacturer: GE

\section{Transducer Specifications:}

Angle-Beam

Type: MWB-45 04E

Frequency: $4 \mathrm{MHz}$

Size: $8 \times 9 \mathrm{~mm}$

Manufacturer: GE

Figure 3.2. Transducer Configurations for Examination of Weld Zone in the Primary Tank Wall 
In the HAZ, the requirement for characterizing cracks that lie perpendicular or parallel to welds in the primary tank wall is described in Figure 3.3. The HAZs are located on either side of the weld and defined as being within 1-in. of the toe of the weld and on the inner three-quarters of the thickness (3/4T) of the plate. These zones are considered most likely to experience stress-corrosion cracking.
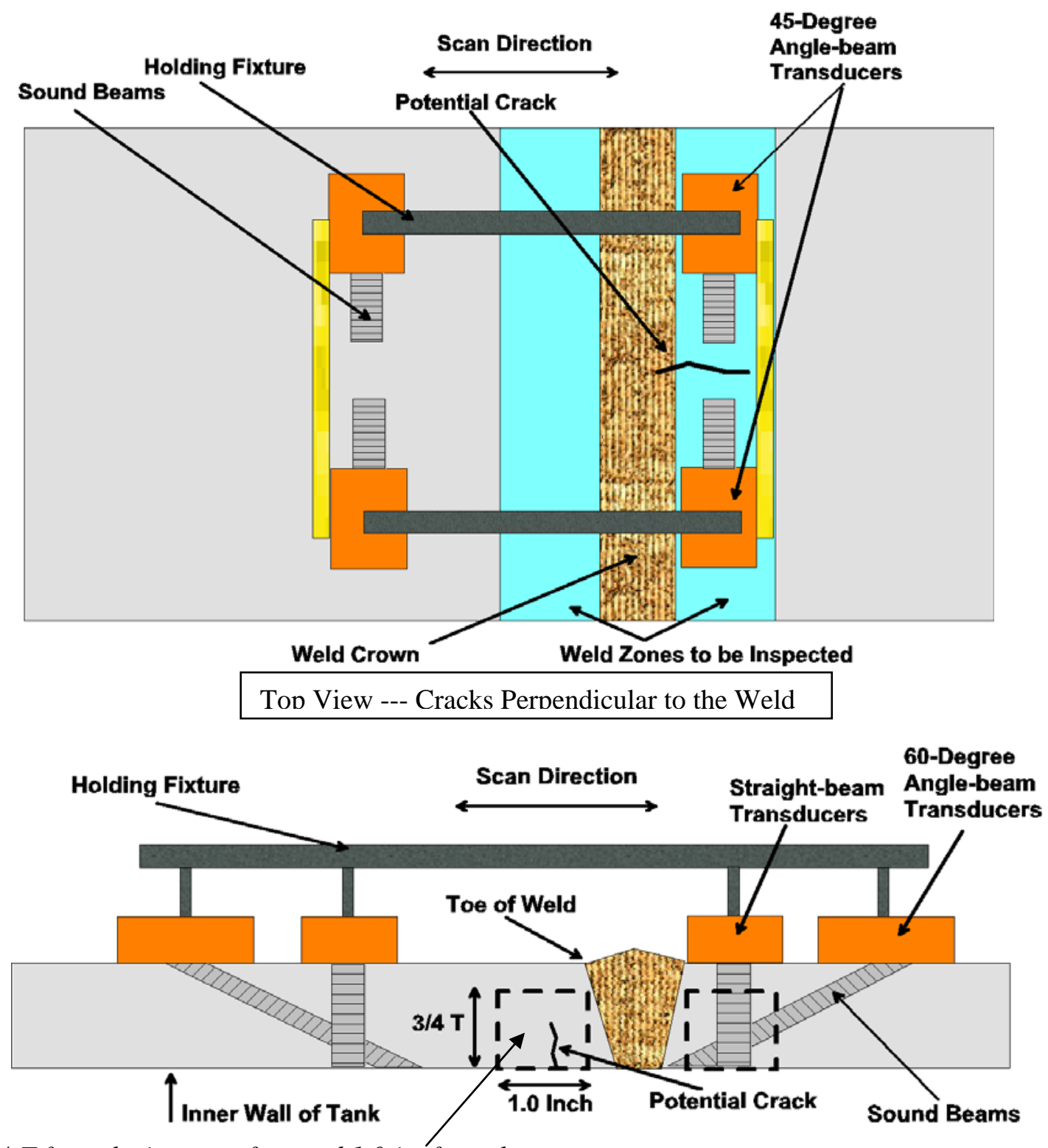

A zone $3 / 4$ T from the inner surface and 1.0-in. from the toe of the weld is to be ultrasonically examined for cracking, corrosion or pitting. Examinations are to be made on both sides of the weld.

$$
\text { End View --- Cracks Parallel to the Weld }
$$

Figure 3.3. Views of the Weld Zone to be Ultrasonically Examined in the Primary Tank Wall 


\subsection{Ultrasonic Examination Location}

Tank 241-AW-101 is located in the Hanford 200 East area in AW Tank Farm. The crawler and associated scanner that hold the transducers were lowered into the 24-in. risers located on the west side (Riser 28) and on the east side (Riser 29) of 241-AW-101. Figure 4.1 provides a graphic of the location of the risers.
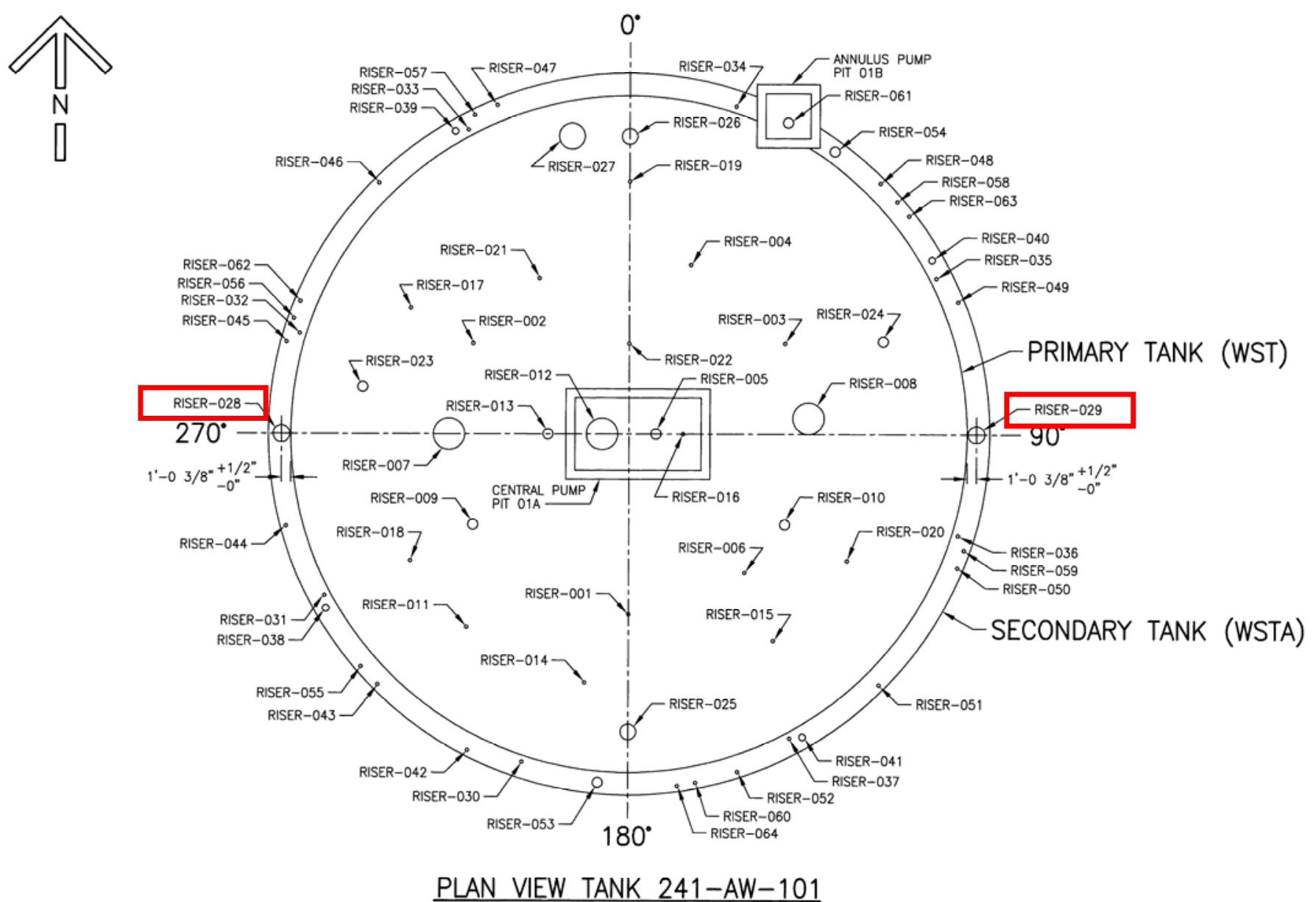

Figure 4.1. UT of Tank 241-AW-101 Riser 28 and Riser 29 
Figure 4.2 describes the areas on the primary wall of Tank 241-AW-101 that were ultrasonically examined from Riser 28 located on the west side of the tank. Two 15-in.-wide vertical scan paths were performed on Plates \#1, \#2, \#3, \#4, and \#5 below the entrance to Riser 28 and the liquid/air interface region on Plate\#1 and the dome haunch. Vertical weld HAZ examinations were done on Plates \#2, \#3, $\# 4$, and \#5, and the horizontal weld HAZ examination was done on the transition Plate \#5 to knuckle weld.

Figure 4.3 describes the areas on the primary wall of Tank 241-AW-101 that were ultrasonically examined from Riser 29 located on the east side of the tank. Two 15-in.-wide vertical scan paths were performed on Plates \#1, \#2, \#3, \#4, and \#5 below the entrance to Riser 29. 
Riser $\mathbb{E}$

N

$\sim \sim$ 17 in

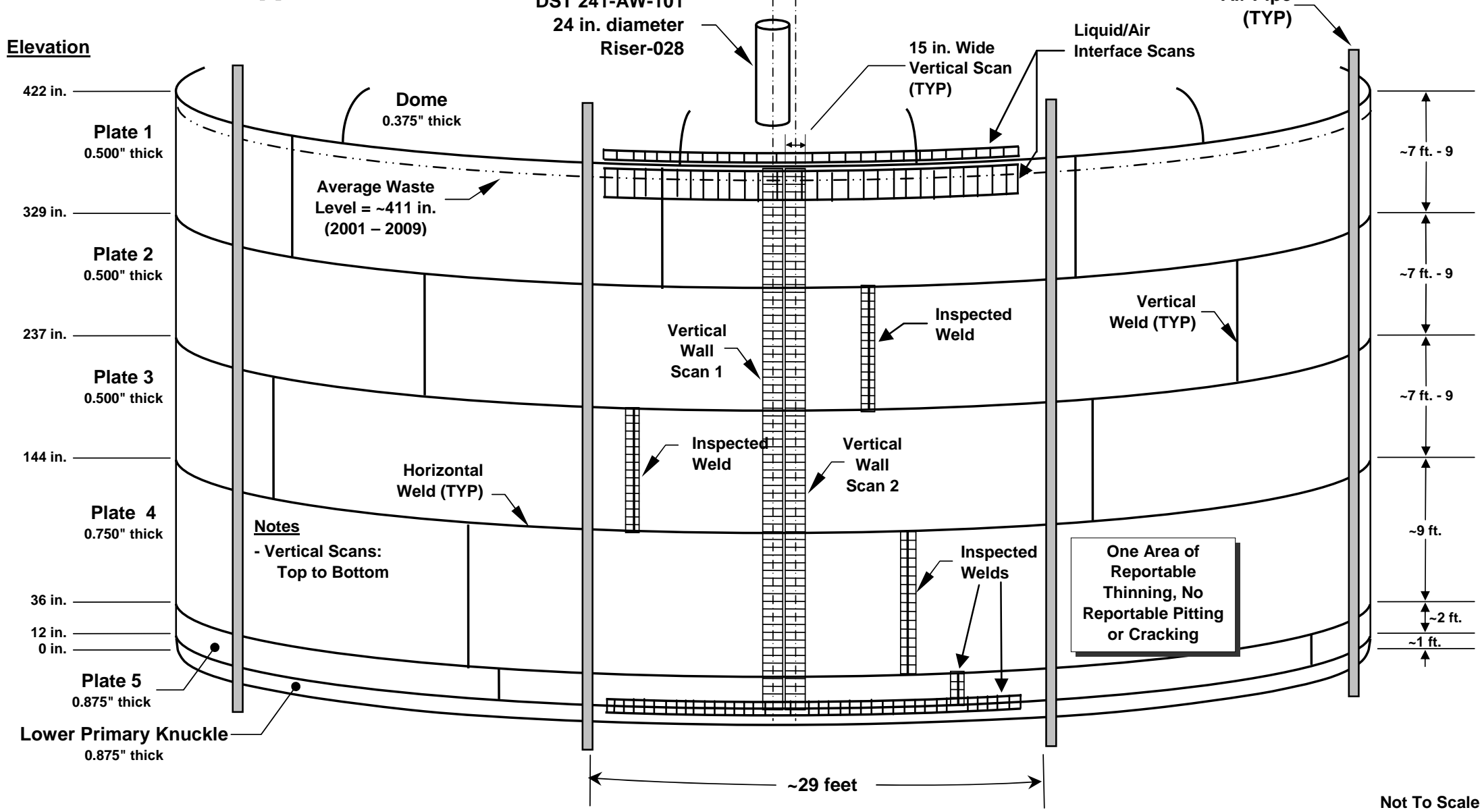

Figure 4.2. Sketch of Scan Paths on 241-AW-101 Primary Tank from Riser 28 


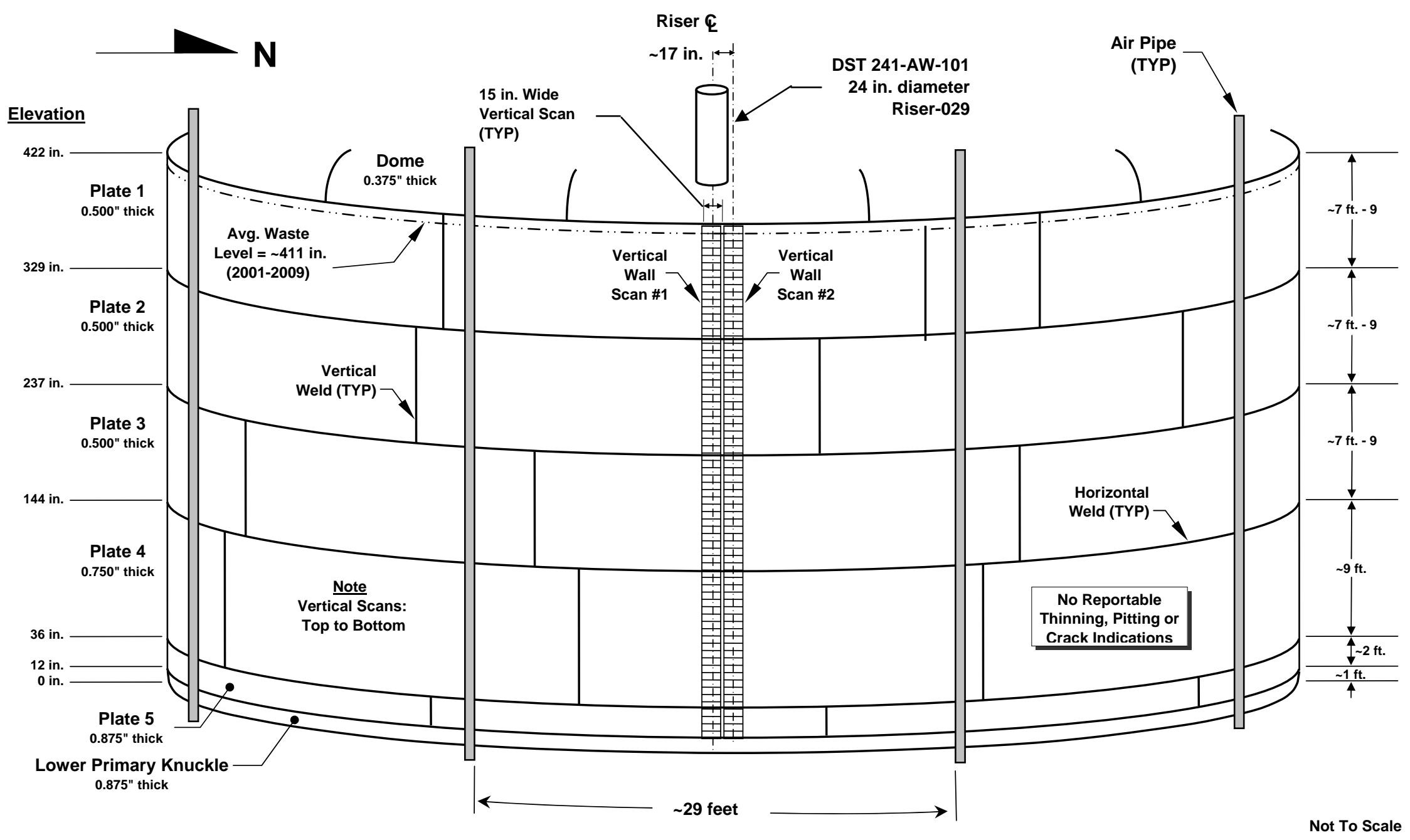

Figure 4.3. Sketch of Scan Paths on Tank 241-AW-101 Primary Tank from Riser 29 


\subsection{Ultrasonic Examination Results}

AFS has provided detailed reports including T-Scan and P-Scan hard copies of all areas that were ultrasonically examined to PNNL for third-party review. The data was analyzed by AFS Level III Mr. Wes Nelson and peer reviewed by JBNDT Level III Mr. Jim Elder. The results of the examination of Tank 241-AW-101 are presented in Figures 5.1, 5.2, 5.3, and 5.4.

Figures 5.1 and 5.2 show the wall thickness examination results for the primary tank wall and the HAZs of both vertical and horizontal welds taken below Riser 28. The examination consisted of two vertical paths beneath the 24 -in. diameter riser. Vertical scan \#1 was 15 -in.-wide on Plate \#1, \#2, \#3, \#4, and \#5 near the centerline of the 24-in. riser. Vertical scan \#2 was adjacent to vertical scan \#1 and was also 15-in.-wide on Plates \#1, \#2, \#3, \#4, and \#5. Vertical scans were conducted in the downward direction. Figures 5.1 and 5.2 display the minimum readings taken in each 15-in.-wide by 12-in.-long area of the scan. Additional horizontal scans were performed at the liquid/air interface on Plate \#1 and on the upper haunch (dome). The HAZs of vertical welds in Plates \#2, \#3, \#4, and \#5 were examined and the HAZ in the horizontal weld between Plate \#5 and the knuckle section was also examined. Weld area exams include approximately 5-in. on each side of the weld and figures 5.1 and 5.2 display the minimum readings taken in each 5-in.-wide by 12-in.-long area of the scan. Areas in the figures that show two measurements in the same box are the result of the vertical scan paths overlapping the horizontal scan paths. In the overlapping areas, both minimum readings from each vertical and horizontal scan paths are given. The gray highlighted area indicates that the minimum wall thickness exceeded the reportable level of $10 \%$ of the nominal wall thickness.

Figures 5.3 and 5.4 show the wall thickness examination results for the primary tank wall taken below Riser 29. The examination consisted of two vertical paths beneath the 24-in. diameter riser. Vertical scan \#1 was 15-in.-wide on Plate \#1, \#2, \#3, \#4, and \#5 near the centerline of the 24-in. riser. Vertical scan \#2 was adjacent to vertical scan \#1 and was also 15-in.-wide on Plates \#1, \#2, \#3, \#4, and \#5. Vertical scans were conducted in the downward direction. Figures 5.3 and 5.4 display the minimum readings taken in each 15-in.-wide by 12-in.-long area of the scan. The green highlighted area indicates that the minimum wall thickness exceeded the $10 \%$ level, but the UT Level III has characterized this as a pit-like indication. None of these pit-like indications exceed the pitting criteria of $25 \%$ of nominal thickness and are therefore not reportable. 


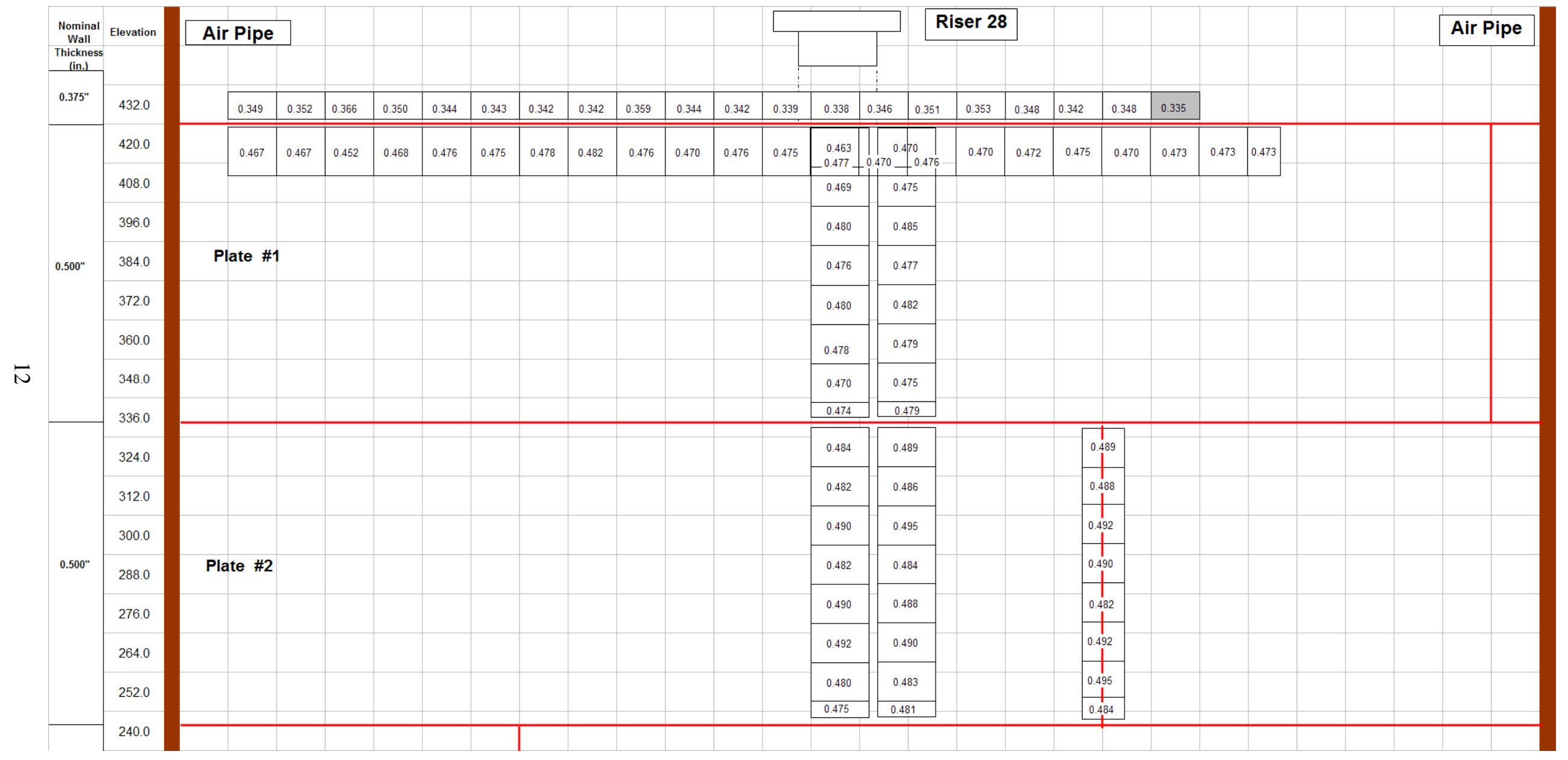

Figure 5.1. UT Data from Tank 241-AW-101 Riser 28 


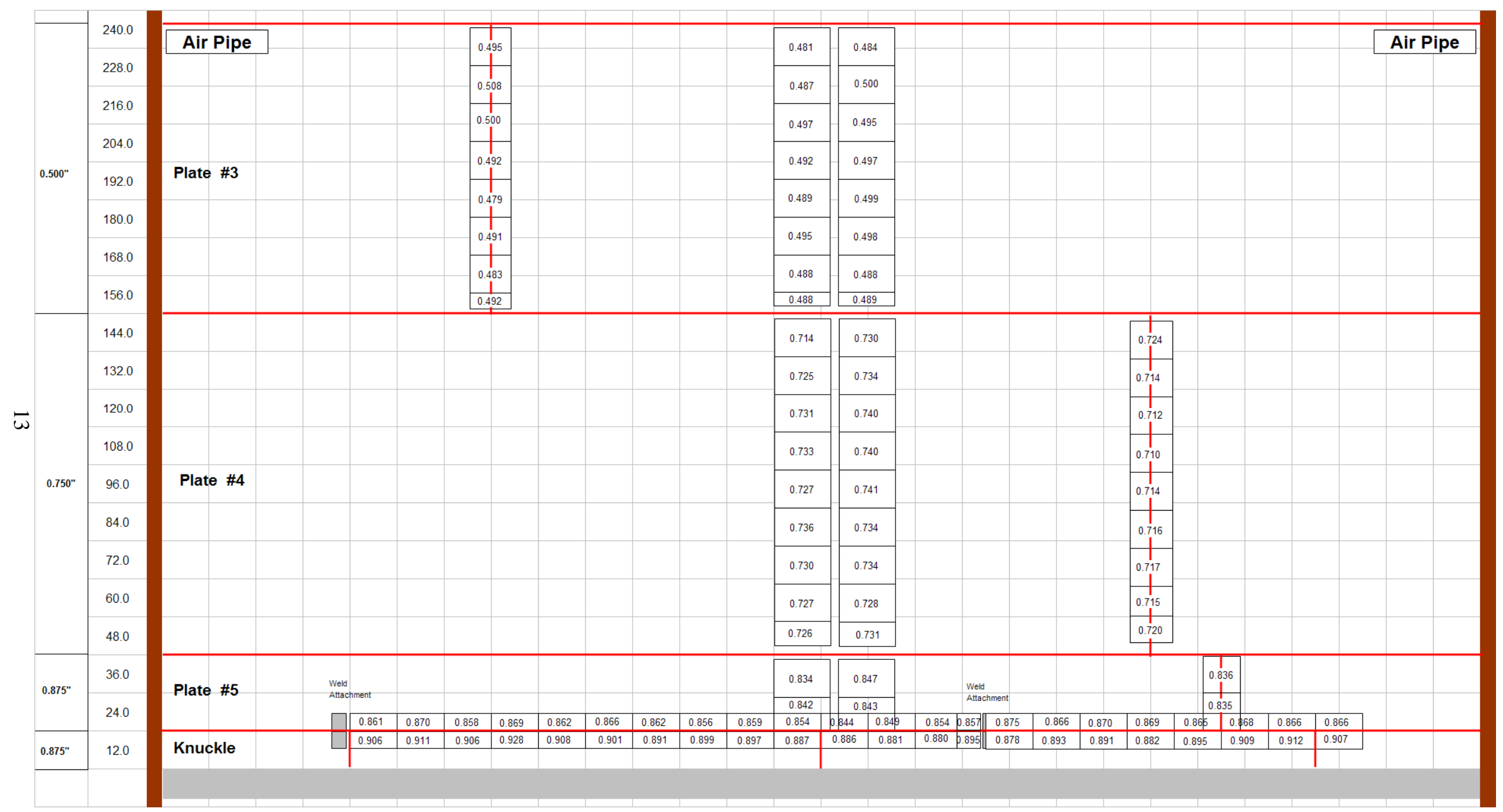

Figure 5.2. UT Data from Tank 241-AW-101 Riser 28 cont. 


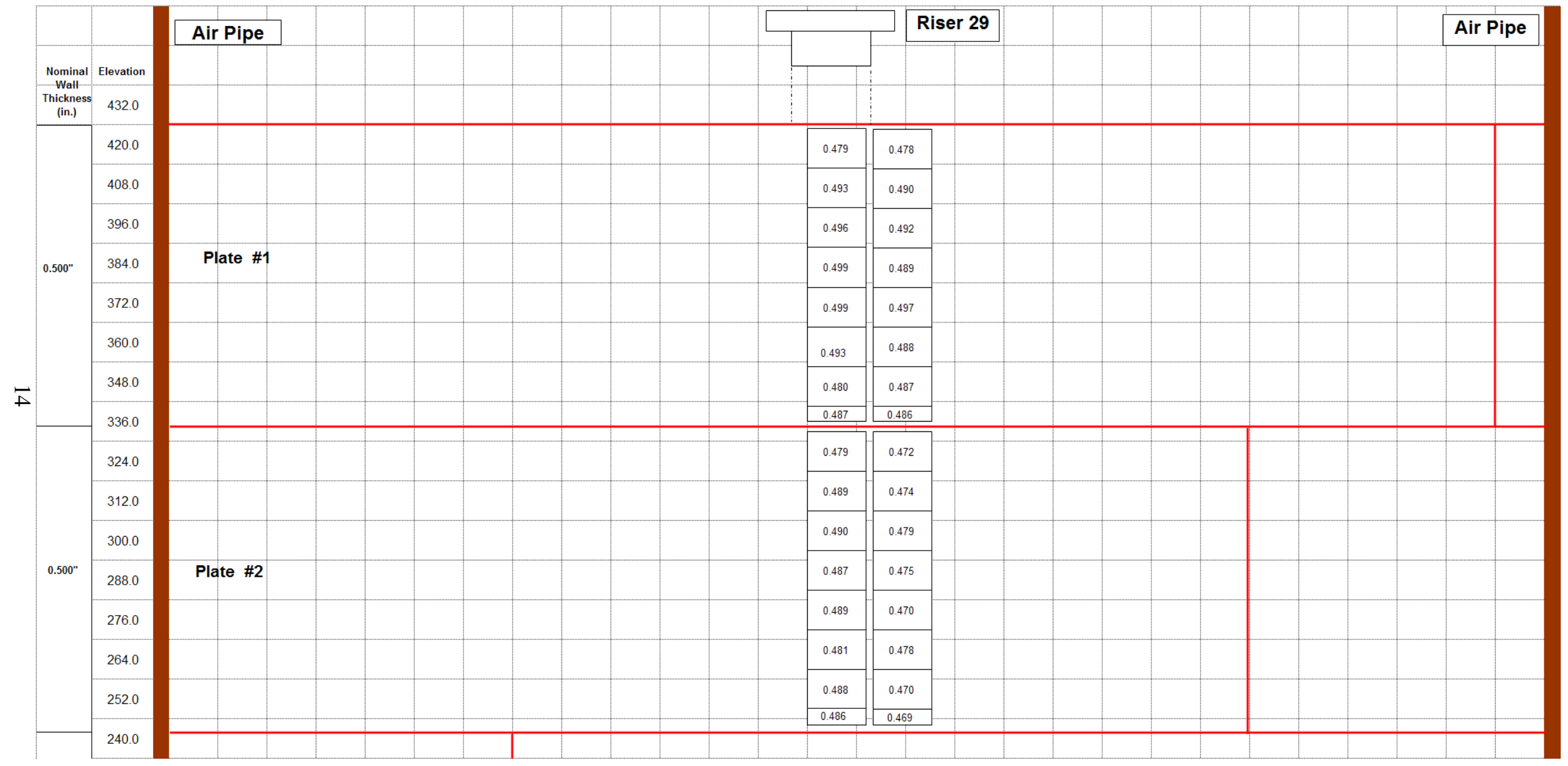

Figure 5.3. UT Data from Tank 241-AW-101 Riser 29 


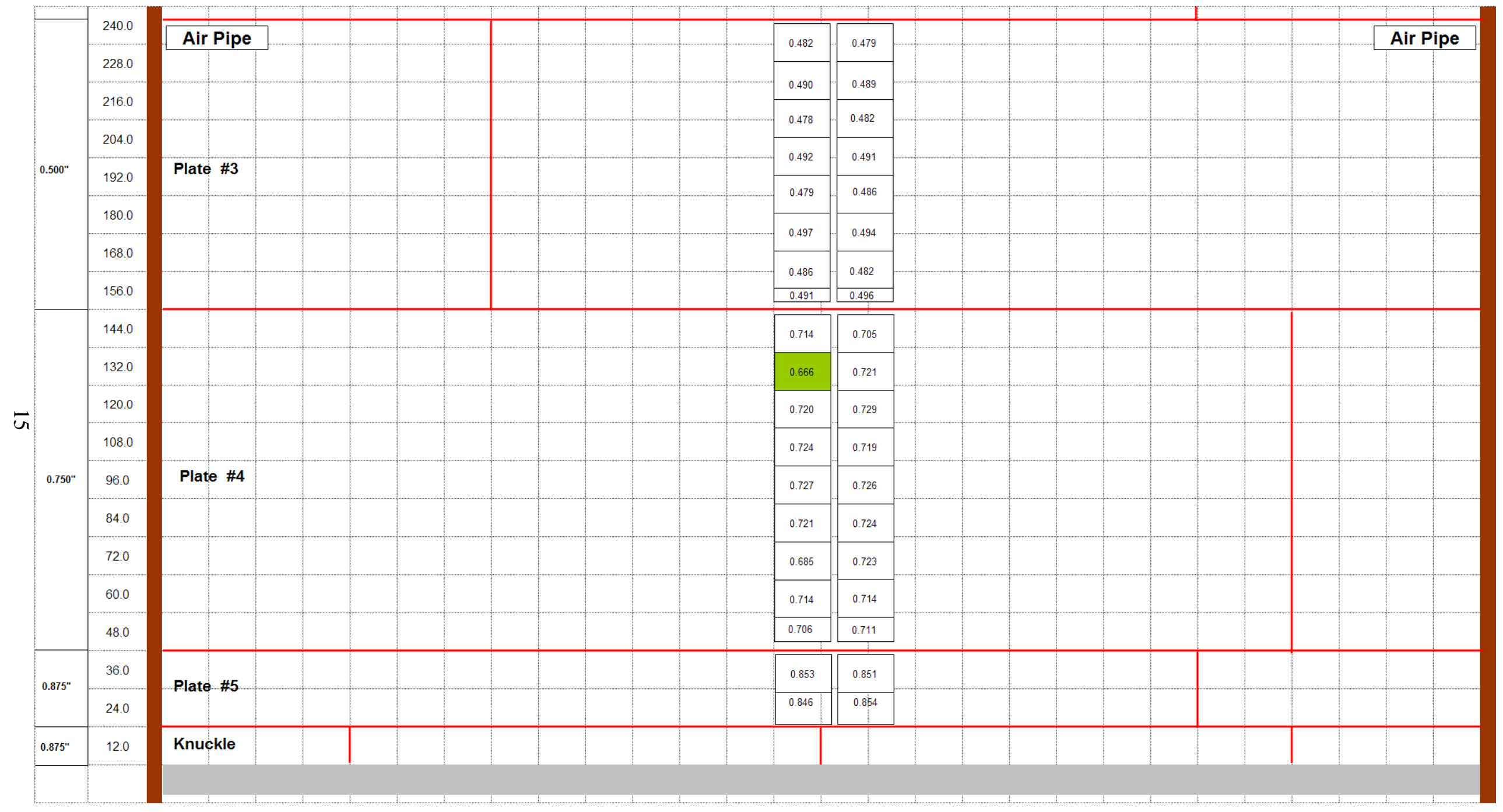

Figure 5.4. UT Data from Tank 241-AW-101 Riser 29 cont. 


\subsection{Ultrasonic Data Statistical Analysis}

\subsection{Extreme Value}

The objective of this section is to estimate a worst case wall condition with respect to thinning (see Weier, Anderson, 2005, for a description of the methodology). If remaining wall thickness were used to estimate such a worst case condition, wall thickness measurements from plates with differing nominal thicknesses could not be combined to fit a common distribution. Extreme value distribution fitting will benefit from having more measurements to fit, so if results can be reasonably combined across plates, this approach is preferred. For this reason, extreme value plate loss is computed instead of using remaining wall thickness. However if the original nominal values for tank wall thicknesses (0.5-in., 0.750-in., and 0.875-in. respectively for Tank 241-AW-101) are used, negative losses are often obtained since remaining wall thickness still exceeds drawing nominal. For this reason UT image maximum values were used to provide a better estimate of original wall thickness than the drawing nominal values. This assumes some areas of plates are in near pristine condition. But of course such maximum values would not be used if they were less than the original drawing nominal thickness.

In previous reports the UT maximum values were only available for the new inspections. For this report, the maximum values were in fact recorded in the old inspection as well. That raises the question of which UT maximum values should be used to better estimate wall thickness under pristine conditions. Note the maximum values were also available from the older inspections for the last two tanks inspected in 2008. However the authors of this report simply didn't note at that time that this did raise such an issue, so it is being addressed for the first time in this Tank 241-AW-101 report. Now it is the case that when the old and new UT maximum values are compared in a later section of this report, the newer maximum results are reduced from the older values. This might suggest that the older UT maximum values are a better estimate of original tank wall thickness, but again the issue can be raised regarding whether such results indicate actual wall thickness loss or systematic measurement differences from old to new inspections.

However, another issue has a bearing on the decision to be made here. In the older inspections, only a single riser was used. Thus we only have maximum values for the plates down a single riser, not down both risers. If we were to use the older UT maximum values for Riser 28 (inspected both times) but the newer UT maximum values for Riser 29 since only they are available, we have immediately introduced a systematic difference between risers since original Riser 28 thicknesses would be reported greater than Riser 29 thicknesses. The goal for extreme value is to combine data around the plate courses, and hopefully across plate course by using wall thickness loss. Such riser differences would immediately defeat this purpose. Therefore in this report only the new UT maximum values are used to estimate an original plate thickness both for Risers 28 and 29. Note that when the first old inspection does contain inspection from both risers, this issue will be raised again, since now the older UT maximums will be available for all plates down both risers, and perhaps the older values should then be used for this extreme value analysis.

Note also that the extra variability due to measurement error has not been separated from the actual 
wall thickness variability here. Therefore when extreme value estimates and bounds are generated using the following methodologies, a worst case "measured wall thickness loss" is being estimated. That is, both the measurement uncertainty associated with the UT maximum values and the UT minimum values, and the actual wall thickness variability all contribute to the overall uncertainties. When we obtain a worst case value, we are then deriving a worst case "measured result" that would be expected if the entire tank were inspected using UT methodology. This is a more extreme value than would be obtained estimating only a worst case wall condition; to do that, measurement error would have to be adequately characterized and removed from consideration. That has not yet been undertaken since appropriate data are not available to do so, but it is a topic of proposed studies.

Note that in this measurement variability issue, we need not be concerned with "systematic" measurement errors since we are taking maximum minus minimum values, so systematic error between the two would simply cancel out. However, we do get two different "random" realizations of measurement error associated with the maximum and minimum values.

Two inspection paths are available down each of two risers for Tank 241-AW-101. For example, in a $\sim 9$-ft. plate (vertical dimension) for one riser, this generates about 8 maximum measured wall thickness values per path (it actually varies from plate to plate depending on plate dimensions). These values were considered over the two paths for each riser/plate combination. The alternative "nominal thickness" selected in this manner then depends somewhat on the pattern of these maximum values, but generally it could be described as approximately the $90^{\text {th }}$ percentile of such measurements. It was considered too extreme to use the largest of the 16 or so maximum values due to potential measurement error then grossly over-estimating the true nominal thickness. In this manner the Figure 6.1 maximum remaining thicknesses were obtained for Tank 241-AW-101.

\begin{tabular}{|c|c|c|c|c|c|}
\hline \multirow{2}{*}{ AW-101 } & \multicolumn{5}{|c|}{ Plate Estimated Nominal } \\
\cline { 2 - 6 } & $\mathbf{1}$ & $\mathbf{2}$ & $\mathbf{3}$ & $\mathbf{4}$ & $\mathbf{5}$ \\
\hline \hline Riser 28 & 0.5175 & 0.5375 & 0.5325 & 0.7775 & 0.8875 \\
\hline Riser 29 & 0.5275 & 0.5275 & 0.5325 & 0.7625 & 0.8975 \\
\hline
\end{tabular}

Figure 6.1. Estimated Nominal Thickness from UT Maxima

The individual UT image minimum values in each path for a plate/riser combination were then subtracted from the estimated maximum value for that plate/riser from Figure 6.1. In this manner 8 or so estimated UT maximum wall thickness losses could be obtained per path for such a plate/riser combination, and then these were combined across the two risers, two paths per riser, so about 32 such losses were available for the entire plate course. This is a relatively minimal amount of data for distribution fitting as performed in this work; this is why combining measurements across plates is desirable.

Note that since two risers are used, the riser variability within the tank does contribute to the overall variability in the results. For this reason an added one-sigma uncertainty, to accommodate riser variability if only a single riser were used, is not added here (see Weier, Anderson, Berman 2005).

The estimated wall thickness maximum losses for Tank 241-AW-101 are shown across plates in Figure 6.2. Box-plots are used to indicate the vertical extent of the measurements within each plate 
course; the rectangles within each box-plot represent the middle $50 \%$ of the measurements. If significant differences are shown between the plates, groupings of like plates are made rather than just combining the losses across all plates. Here Plate \#4 has two extreme outlying values with the distribution of wall thickness losses extending to higher values. Without the two outliers Plates \#2 and \#4 have very similar distributions with somewhat greater loss than is observed for Plates \#1, \#3, and \#5, which are much like each other, especially in the upper tails that impact the extreme value results the most. For this reason Plate \#2 and \#4 measurements are combined into one group and considered with and without the two Plate \#4 outliers to demonstrate their considerable impact on results. Plates \#1, \#3, and \#5 are similarly combined but with no outlier issue. All plates are then combined as well, again being considered with and without the two Plate \#4 outliers.

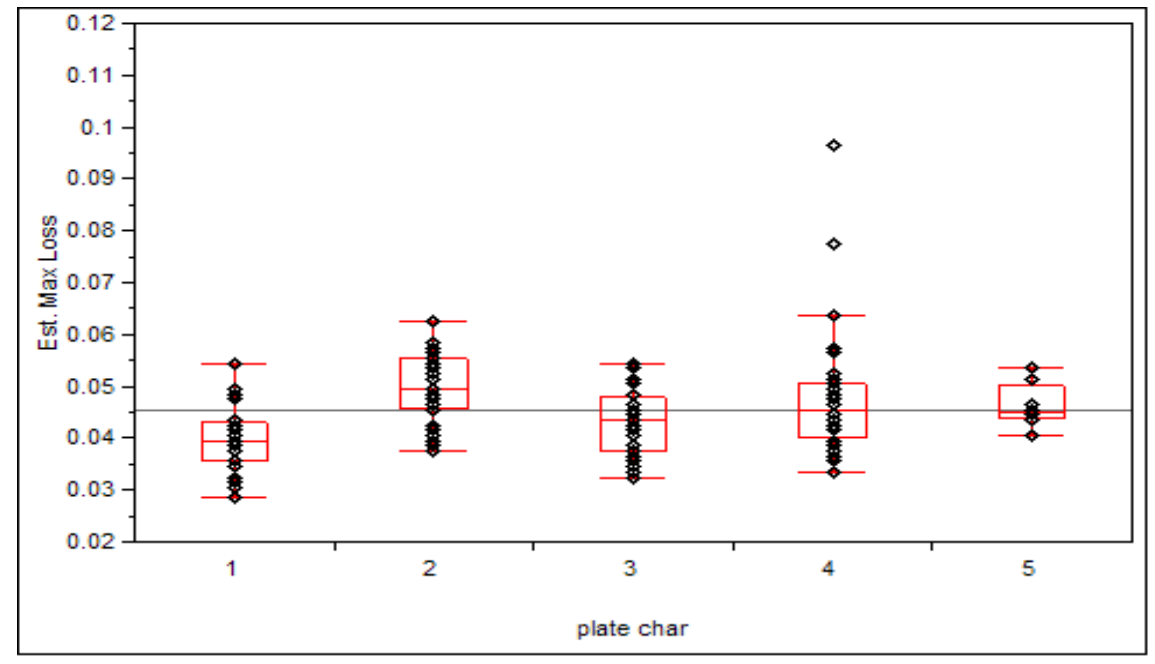

Figure 6.2. Estimated Maximum Loss by Plate

The three histograms in Figure 6.3 show estimated maximum wall thickness losses respectively for plate courses \#2 and \#4 combined, for plate courses \#1, \#3, and \#5 combined, and then for all plate courses combined. Three-parameter Weibull distributions are fit to these histograms and are shown as the smooth black curves. For the top and bottom histograms a second distribution is fit (red dashed curve) that results when the two outlying Plate \#4 values are omitted. The total surface area of a plate course combination is computed, and thus the number of 15-in. by 12 -in. UT images needed to $100 \%$ inspect the entire plate course combination obtained. The percentile of the distribution that then corresponds to the maximum expected loss among this many UT images, based on the distribution fit to the histogram, is considered as the expected estimated worst case loss in that plate course combination.

The number of measurements available, and the quality of the fit of the Weibull distribution, affect the uncertainty in the estimated Weibull parameters, and in turn, the uncertainty in this estimated worst case loss. Therefore 95\% confidence bounds on the worst case losses are also computed using these uncertainties.

Consider first the middle histogram for Plates \#1,\# 3, and \#5. The longer and bolder black vertical arrow to the immediate right of the histogram is the extreme value estimate that might be expected if this 
entire plate course combination were $100 \%$ UT-inspected around its entire tank circumference. Its value is 0.064-in. as given in the first column of values in the table in Figure 6.4. The statistical 95\%

confidence bound is then the smaller arrow on this Figure 6.3 histogram at value 0.069 -in. and in the next row of the Figure 6.4 table. This value incorporates the various sources of uncertainty to predict an upper bound on the worse case measured wall thickness loss in the plate course combination. The bottom value in the table is the number of measurements available in the plate course combination. Recall these losses are to be compared to the estimated maximum values in Figure 6.1, not to drawing nominal thicknesses.
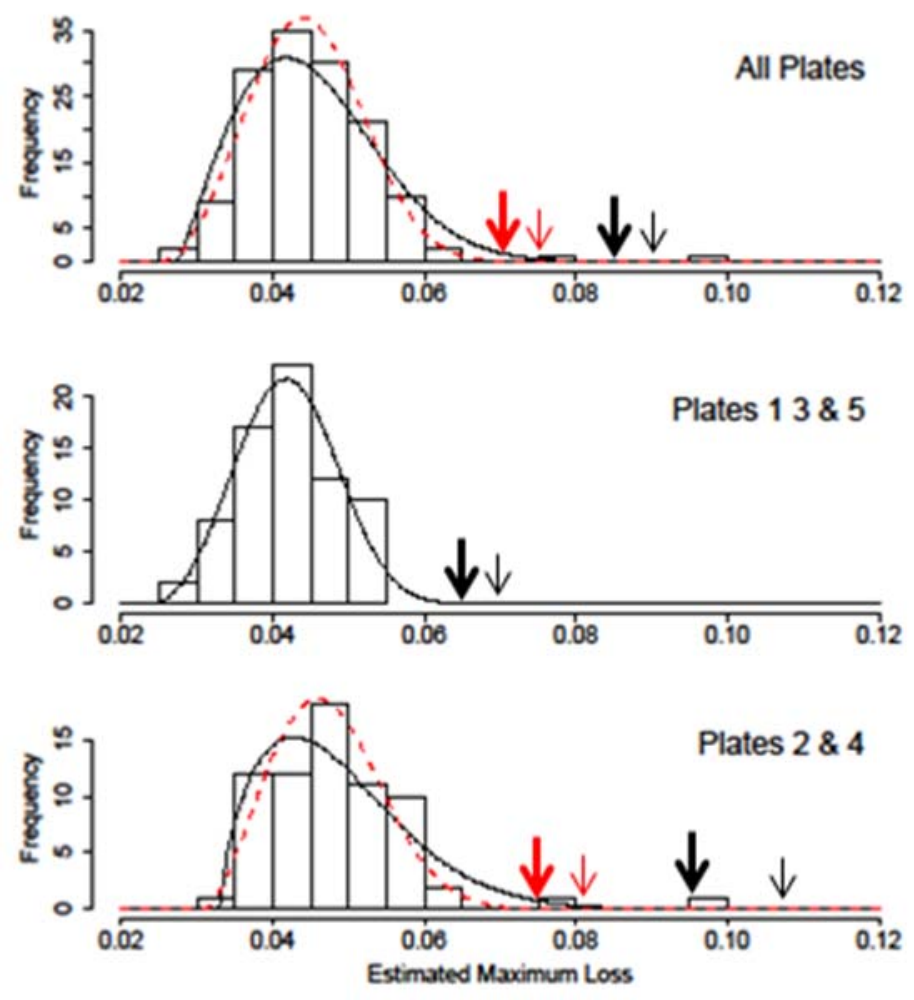

Figure 6.3. Weibull Distribution Fits to UT Maximum Wall Thickness Loss for Plate Course Combinations

The bottom histogram in Figure 6.3 is for Plates \#2 and \#4 combined. The black curve and arrows are again the Weibull distribution, extreme value estimate, and its confidence bound when the two outlying values are included. The red dashed curve and the red arrows are obtained when the two outliers are omitted. The dramatic impact of them is then obvious. The corresponding values are again given in Figure 6.4 table under the so-labeled columns. The notation "w.o." indicates "without outliers". Values are also shown in a red font for the w.o. cases.

The top histogram in Figure 6.3 is for all Plates combined, again with and without the two Plate \#4 outlying values. The outlying values have somewhat less impact here since they are included with a considerably larger set of smaller values now than was the case for just Plates \#2 and \#4 alone.

As stated earlier, included in the Figure 6.4 table are: 1) the estimated extreme value loss expected 
for the plate course combinations around the entire circumference of the tank, 2) the $95 \%$ confidence bound for this extreme value loss, and 3) the number of measurements in the plate course combination. The first column of values for Plates \#1, \#3, and \#5 are quite reasonable. The outlying values have considerable impact, and they apparently come from some other physical condition that is not generating the smaller values. Fitting a statistical distribution across both the smaller values and the two outliers is therefore probably inappropriate. Instead the Plate \#2 and \#4 results without the outliers (red font) are probably the best statistical estimates of extreme values. But then it is understood that around the circumference of the tank there are likely some other more extreme cases caused by whatever physical phenomenon caused these. We certainly cannot fit a separate distribution to only two points to make some kind of worse case prediction for these more extreme cases.

The combined plate results in the final columns of the table are not recommended since the plate differences were fairly distinct, especially in the upper tails of the distributions, as observed in Figure 6.2.

\begin{tabular}{|c||c||c|c||c|c|}
\hline \multirow{2}{*}{$\begin{array}{c}\text { AW-101 } \\
\text { Extreme Values }\end{array}$} & \multicolumn{5}{|c|}{ Plate Courses } \\
\cline { 2 - 6 } & $\mathbf{1 , 3 , 5}$ & $\mathbf{2 , 4}$ & $\begin{array}{c}\mathbf{2 , 4} \\
\text { w.o. }\end{array}$ & $\begin{array}{c}\text { All } \\
\text { Combined }\end{array}$ & $\begin{array}{c}\text { Combined } \\
\text { w.o. }\end{array}$ \\
\hline \hline Estimate & 0.064 & 0.095 & 0.074 & 0.085 & 0.071 \\
\hline 95\% Bound & 0.069 & 0.107 & 0.081 & 0.091 & 0.076 \\
\hline Measurements & 72 & 68 & 66 & 140 & 138 \\
\hline
\end{tabular}

Figure 6.4. Tank 241-AW-101 Wall Thickness Extreme Value Loss Estimates and Bounds

\subsection{Riser Differences}

Original analyses of Tank 241-AY-101 described in Weier, Anderson, Berman 2005 showed wall thickness differences between the four risers used. This led to requirements for UT inspection for using at least two risers. But after the several tanks were so inspected during 2007, more multiple riser results became available. For the analysis of riser differences from those 2007 tanks, riser differences were not indicated (see Weier, Pardini 2007). This led to the consideration for reducing inspections from two paths from each of two risers to perhaps three or four paths from a single riser. But through 2008 and into 2009, the two riser, two paths per riser, convention has been continued. Therefore riser differences will continue to be examined. During 2008 inspections, riser differences ranged from being marginally statistically significant to no significant difference at all. Examination of the AW-101riser differences is the purpose of this section.

Two paths were inspected in each of Risers 28 and 29. Results were averaged over the two paths per riser at each elevation for each riser. Riser differences at each elevation were then computed by subtracting the Riser 29 means from the Riser 28 means. Figure 6.5 shows the results; from left to right in the figure are respectively the UT image minimum values, average values, and maximum values.

The UT average riser differences would be considered statistically significant with Riser 28 more 
often exceeding Riser 29 over the various elevations. Note that the mean difference is about 0.005 -in.

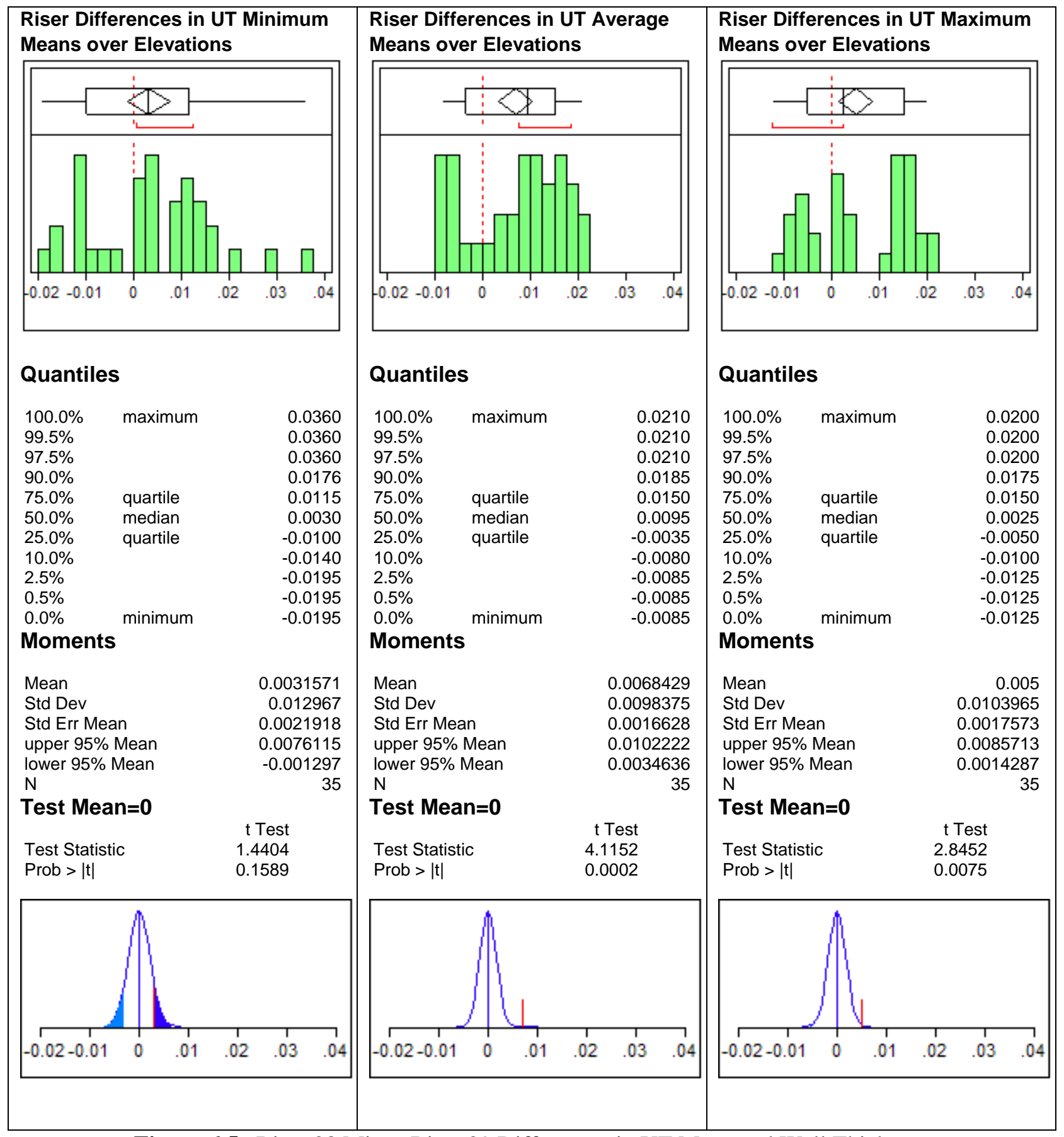

Figure 6.5. Riser 28 Minus Riser 29 Differences in UT Measured Wall Thickness 
The UT maxima show a more marginal statistical difference. Histograms centered at zero at the top of the figure indicate these differences along with statistical tests below them. The more blue-shaded area visible on the bottom figures, the less difference is indicated. The UT minimum values would not be considered statistically different between the risers, but again Riser 28 does exceed Riser 29 more often than not.

Note, as might be expected, the greater variability in the riser differences in UT image minima than is observed for UT image averages or maxima. This is also part of the reason for the lack of a statistical difference; to be significant the mean difference has to be larger relative to the variability over the different elevations. Figure 6.6 shows this variability over the elevations with the vertical dashed lines indicating plate course boundaries. Note that Plates \#1 and \#5 actually had riser 29 measurements generally exceeding those of Riser 28 , but this was reversed for the other plates.

UT Minima Differences

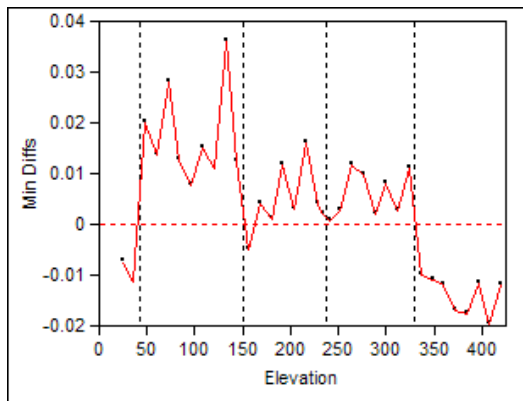

UT Averages Differences

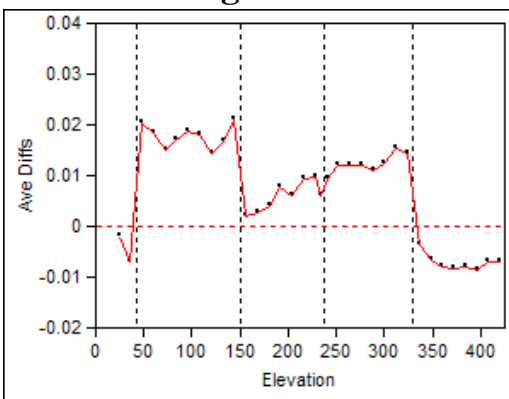

UT Maxima Differences

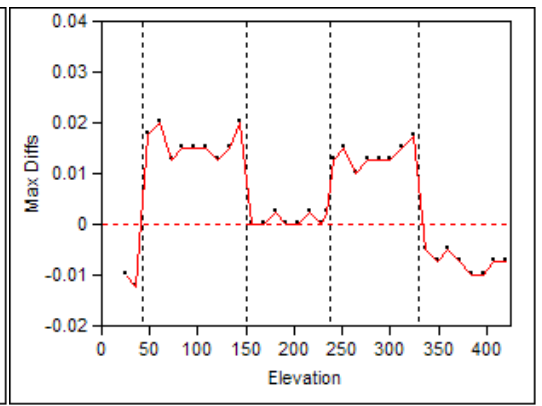

Figure 6.6. Riser 28 minus Riser 29 Differences

The greatest riser differences observed continues to be those in the first tank examined in this manner; this was Tank 241-AY-101 in which four different risers were used during the inspection. Since then either no significant riser differences, or only marginally significant ones, have been observed in other tanks. The convention of using two risers is probably warranted to incorporate the extra variability that is sometimes observed.

\subsection{Comparison between 2001 and 2009 Data}

Two paths were inspected in essentially the same locations under Riser 28 in both the recent inspection and that performed in the prior Tank 241-AW-101 inspection in 2001. Individual UT images from 2001 and 2009 can therefore be compared within paths and at the various elevations. That is the purpose of this section.

Note that a value from the older inspection indicated an area of much greater wall thinning than in its surrounding area, by about 0.050 -in. Considerable effort was made to locate that area in the new inspection, but it was not found. It is expected to be in error in the older inspection. Since it generates a very large wall thickness gain in the minimum wall thickness at this location from the old to new inspection, it results in a very large outlying value, and it was deleted from these analyses. For this reason, gaps in Path 1 plots at that elevation, and reduced sample sizes, can be observed in the following. 
Figure 6.7 shows the distributions of "Old minus New" measurements over UT images. The mean difference in the 70 UT minima measurements that can be compared in this manner is about 0.008 -in. (this is greater wall thickness loss, or equivalently reduced wall thickness, in 2009 than in 2001). For the UT average measurements, this mean difference is 0.007 -in., and for UT maximum measurements, the mean difference is 0.015 - in. The resolution is less for the maxima since it appears results were generally only recorded to the nearest 0.010 -in. in 2001 and to the nearest 0.005 -in. in 2009. The red vertical dashed lines on the histograms at the top of the figure indicate no difference. T-tests show statistically significant differences in the old and new measurements as indicated by the lack of blue shading in the curves at the bottom of the figure and the separation of the observed red vertical lines from the blue distribution which would be expected to contain comparison results if there really were no underlying differences between 2001 and 2009.

As a reminder, such "old minus new" measurement differences could reflect actual wall thickness decreases, systematic changes in the way measurements were made then and now, or a combination of the two. Investigations of the UT measurement methodology are underway to examine potential causes of measurement differences, in particular so they can be better controlled in the long term to better facilitate accurate old to new comparisons in future inspections.

In Figure 6.8 differences from nominal wall thickness for 2001 and 2009 are plotted for each path, for the UT minima, averages, and maxima. The red and blue curves are respectively for 2001 and 2009.

Since the losses are now "drawing nominal minus measured" wall thickness, negative values indicate the wall thicknesses are still greater than the original drawing nominal thicknesses. Only the UT minimum values are generally less than the original drawing nominal. Plates \#1 through \#5 go from right to left on the plots since the higher elevations on the horizontal axis are to the right. The blue curves being above the red curves indicate that thinner wall thickness measurements generally resulted in the new inspection. Even if the losses are real, this is only about 0.001 -in. loss per year. 
Old Minus New (Riser 28)

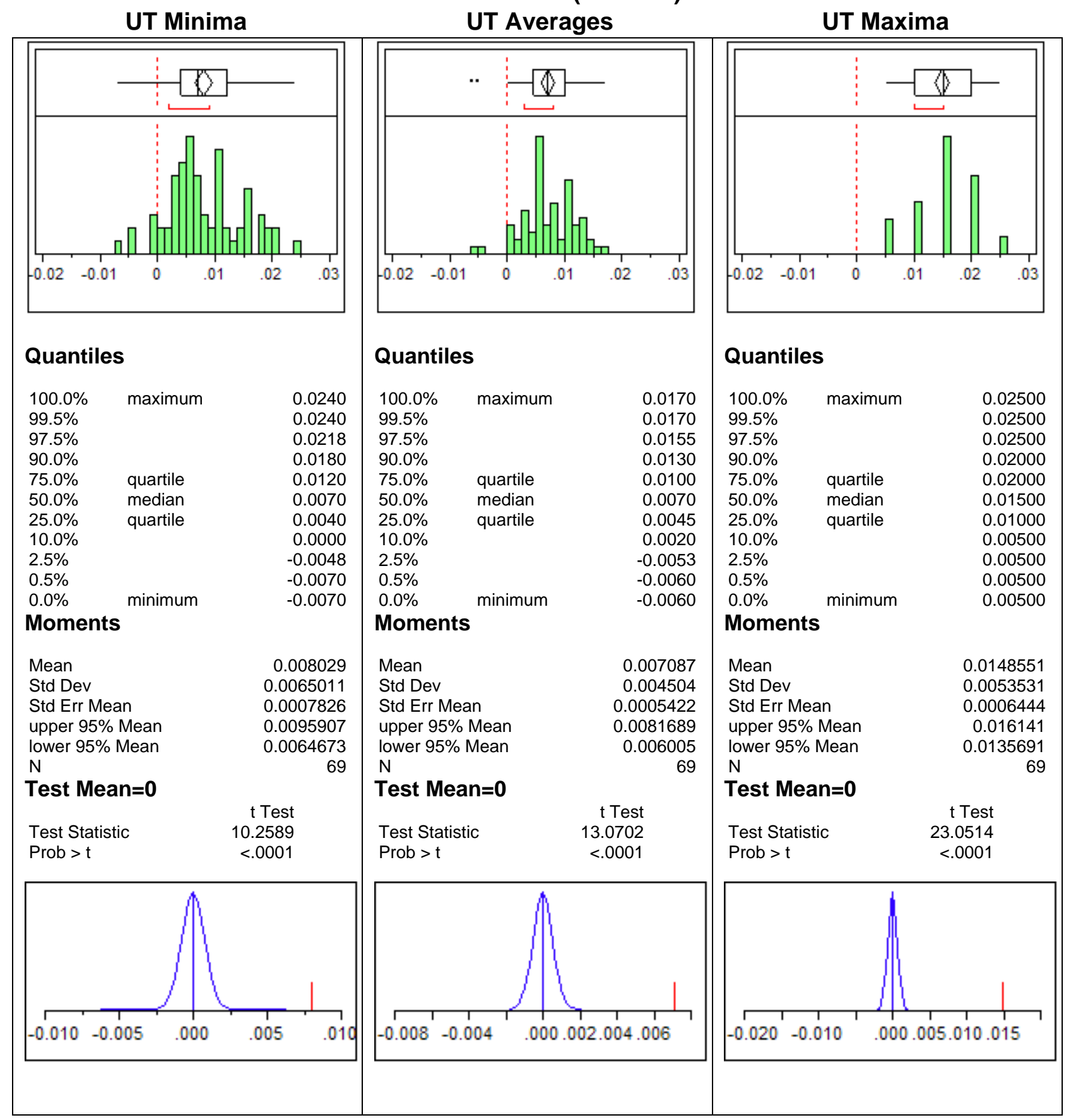

Figure 6.7. Year 2001 minus Year 2009 Differences 


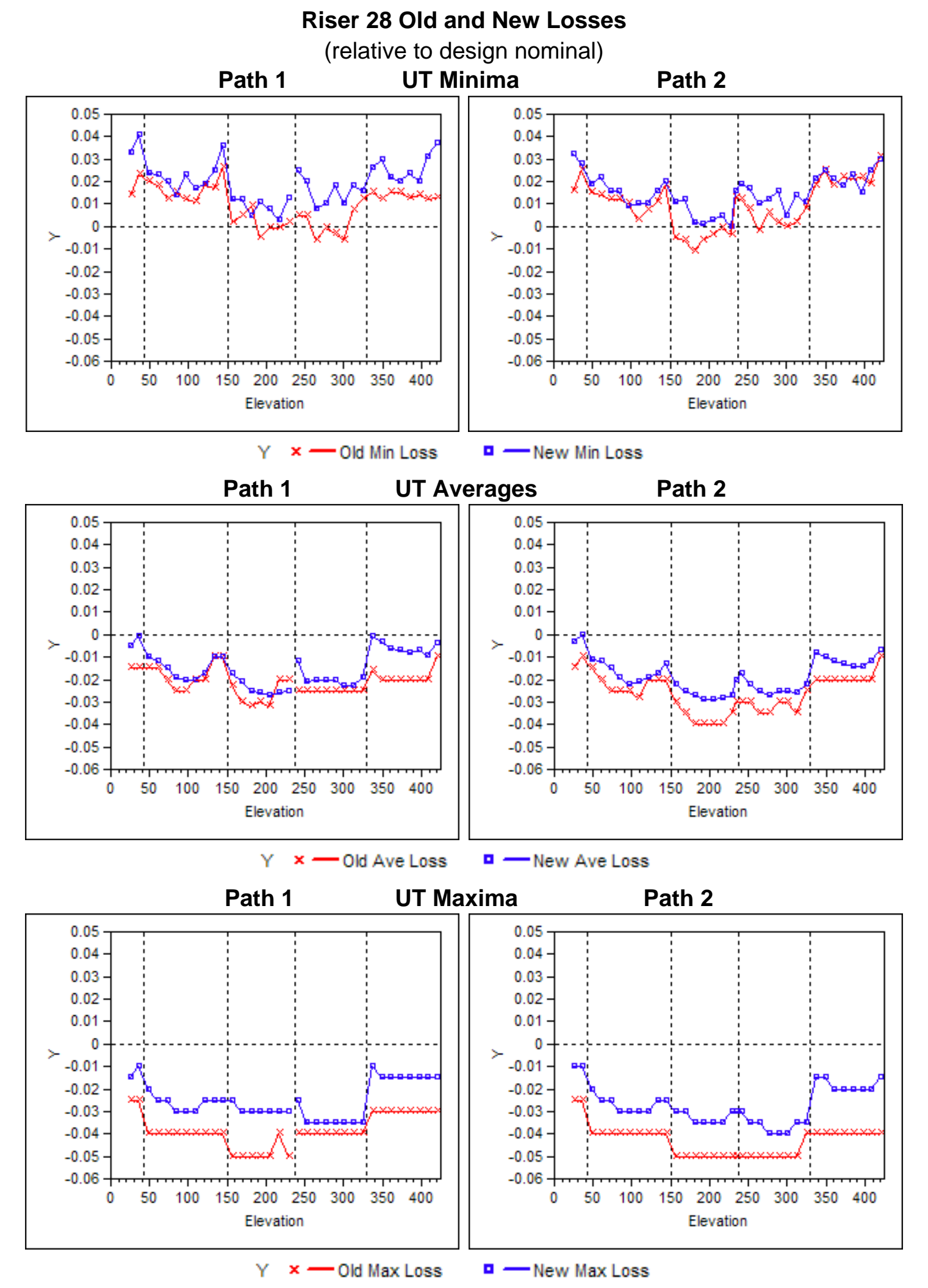

Figure 6.8. Year 2001 versus Year 2009 Measurement Paths 


\subsection{Conclusions}

The results of the examination of Tank 241-AW-101 have been evaluated by PNNL personnel. The ultrasonic examination consisted of two vertical 15-in.-wide scan paths over the entire height of the tank and the heat-affected zone (HAZ) of four vertical welds and one horizontal weld and the liquid/air interface on Plate \#1 and the upper haunch (dome) from Riser 28. The examination also included two vertical 15-in.-wide scan paths over the entire height of the tank from Riser 29. The examination was performed to detect any wall thinning, pitting, or cracking in the primary tank wall.

\subsection{Primary Tank Wall Vertical Scan Paths}

Two 15-in.-wide vertical scan paths were performed on Plates \#1, \#2, \#3, \#4, and \#5 from Riser 28. The plates were examined for wall thinning, pitting, and cracks oriented vertically on the primary tank wall. The results indicated that the minimum thicknesses in the areas that were scanned are as follows:

- The nominal thickness in Plate \#1 is 0.500-in. and the minimum thickness in this area was 0.463in. Plate \#1 results indicate no areas that exceed the minimum thinning reportable level of $10 \%$ of the nominal thickness. No pitting or vertical crack-like indications were detected in Plate \#1.

- The nominal thickness in Plate \#2 is 0.500-in. and the minimum thickness in this area was 0.475in. Plate \#2 results indicate no areas that exceed the minimum thinning reportable level of $10 \%$ of the nominal thickness. No pitting or vertical crack-like indications were detected in Plate \#2.

- The nominal thickness in Plate \#3 is 0.500-in. and the minimum thickness in this area was 0.481in. Plate \#3 results indicate no areas that exceed the minimum thinning reportable level of $10 \%$ of the nominal thickness. No pitting or vertical crack-like indications were detected in Plate \#3.

- The nominal thickness in Plate \#4 is 0.750-in. and the minimum thickness in this area was 0.714in. Plate \#4 results indicate no areas that exceed the minimum thinning reportable level of $10 \%$ of the nominal thickness. No pitting or vertical crack-like indications were detected in Plate \#4.

- The nominal thickness in Plate \#5 is 0.875-in. and the minimum thickness in this area was 0.834in. Plate \#5 results indicate no areas that exceed the minimum thinning reportable level of $10 \%$ of the nominal thickness. No pitting or vertical crack-like indications were detected in Plate \#5.

Two 15-in.-wide vertical scan paths were performed on Plates \#1, \#2, \#3, \#4, and \#5 from Riser 29. The plates were examined for wall thinning, pitting, and cracks oriented vertically on the primary tank wall. The results indicated that the minimum thicknesses in the areas that were scanned are as follows:

- The nominal thickness in Plate \#1 is 0.500-in. and the minimum thickness in this area was 0.478in. Plate \#1 results indicate no areas that exceed the minimum thinning reportable level of $10 \%$ of the nominal thickness. No pitting or vertical crack-like indications were detected in Plate \#1.

- The nominal thickness in Plate \#2 is 0.500-in. and the minimum thickness in this area was 0.469in. Plate \#2 results indicate no areas that exceed the minimum thinning reportable level of $10 \%$ of the nominal thickness. No pitting or vertical crack-like indications were detected in Plate \#2.

- The nominal thickness in Plate \#3 is 0.500-in. and the minimum thickness in this area was 0.478in. Plate \#3 results indicate no areas that exceed the minimum thinning reportable level of $10 \%$ of the nominal thickness. No pitting or vertical crack-like indications were detected in Plate \#3. 
- The nominal thickness in Plate \#4 is 0.750-in. and the minimum thickness in this area was 0.666in. Plate \#4 results indicate one area that exceeded the minimum thinning reportable level of $10 \%$ of the nominal thickness; however the UT Level III has determined the indication to be a pit which does not meet the reportable level of $25 \%$ for a pit indication. No vertical crack-like indications were detected in Plate \#4.

- The nominal thickness in Plate \#5 is 0.875-in. and the minimum thickness in this area was 0.846in. Plate \#5 results indicate no areas that exceed the minimum thinning reportable level of $10 \%$ of the nominal thickness. No pitting or vertical crack-like indications were detected in Plate \#5.

\subsection{Primary Tank Wall Weld Scan Paths}

The HAZ of vertical welds in Plates \#2, \#3, \#4, and \#5 from Riser 28 were examined for wall thinning, pitting and cracks oriented either perpendicular or parallel to the weld. The results indicated that the minimum thicknesses in the weld areas that were scanned are as follows:

- The nominal thickness in Plate \#2 is 0.500-in. and the minimum thickness in this weld area was 0.482 -in. There were no areas of wall thinning that exceeded the reportable level of $10 \%$ of the nominal thickness. No pitting or crack-like indications were detected in the weld areas in Plate \#2.

- The nominal thickness in Plate \#3 is 0.500 -in. and the minimum thickness in this weld area was 0.483 -in. There were no areas of wall thinning that exceeded the reportable level of $10 \%$ of the nominal thickness. No pitting or crack-like indications were detected in the weld areas in Plate \#3.

- The nominal thickness in Plate \#4 is 0.750-in. and the minimum thickness in this weld area was 0.710 -in. There were no areas of wall thinning that exceeded the reportable level of $10 \%$ of the nominal thickness. No pitting or crack-like indications were detected in the weld areas in Plate \#4.

- The nominal thickness in Plate \#5 is 0.875-in. and the minimum thickness in this weld area was 0.835 -in. There were no areas of wall thinning that exceeded the reportable level of $10 \%$ of the nominal thickness. No pitting or crack-like indications were detected in the weld areas in Plate \#5.

The HAZ of the horizontal weld between Plate \#5 and the tank knuckle from Riser 28 was examined for wall thinning, pitting and cracks oriented either perpendicular or parallel to the weld. The results indicated that the minimum thickness in the weld area with nominal thickness of 0.875-in. on Plate \#5 was 0.844 -in. The minimum thickness in the weld area with nominal thickness of 0.875 -in. on the knuckle was 0.878 -in. There were no areas of wall thinning that exceeded the reportable level of $10 \%$ of the nominal thickness. No pitting or crack-like indications were detected in the weld areas on Plate \#5 side or on the knuckle side of the horizontal weld.

\subsection{Primary Tank Wall Liquid/Air Interface Horizontal Scan Paths}

Two horizontal scan paths were performed in the liquid/air interface region on Plate \#1 and the upper haunch (dome) of the primary tank. The areas were examined for wall thinning on the primary tank wall. 
The scan on Plate \#1 with nominal thickness of 0.500-in. was 15-in. wide on the upper portion of the plate near the haunch weld. The minimum thickness in this area was 0.452-in. There were no areas of wall thinning that exceeded the reportable level of $10 \%$ of the nominal thickness on Plate \#1. The second scan was 5.5-in. wide on the upper haunch (dome) with nominal thickness of 0.375-in. of the primary tank near the dome to Plate \#1 weld. There was one area with a minimum thickness of 0.335 -in. that exceeded the reportable level of $10 \%$ of the nominal thickness.

\subsection{Ultrasonic Data Statistical Analysis}

Extreme Value: Extreme value measured wall thickness losses were estimated within plate/riser combinations so results could potentially be evaluated across plate courses with differing nominal thickness. Since current remaining wall thickness typically still often exceeds drawing nominal, thereby generating negative losses, UT image maximum values were used instead to determine estimated nominal wall thickness per plate/riser combination. These thicknesses tended to run from drawing nominal up to about to nearly 0.040 -in. greater. They in turn were used with each UT image minimum value to determine estimated wall thickness loss per image. These losses which were then combined for a plate course over two risers, two paths per riser.

Tank 241- AW-101is among the first tanks to have UT image maximum values available from the original older inspection. Since only one riser was used, the maxima were not used here for one riser, and not the other, since it would introduce a systematic difference between risers. However, when the first older inspections are encountered that do have two risers used, then an issue will be raised on whether the best estimates of the original plate wall thicknesses are from the old or new UT image maxima.

Three-parameter Weibull distributions were fit to plate course combinations of Plates \#2 and \#4 and Plates\# 1, \#3, and \#5 since somewhat greater losses were indicated in Plates \#2 and \#4. Plate \#4 contained two large outlying loss values that have large impact on results. For this reason results were given for Plates \#2 and \#4 combined, and for all plates combined, both with and without the two outlying values to show their impact.

For Plates \#1, \#3, and \#5 combined, an estimated worst case extreme value loss around the tank is 0.064-in. This loss has 95\% statistical confidence bound of 0.069-in. Note these losses are relative to estimated maximum plate thicknesses meant to approximate original wall thicknesses and are thereby greater than drawing nominal. This generates an estimated worst case measured wall thickness loss since both measurement variability and actual wall thickness variability are included in the estimation process.

The corresponding Plate \#2 and \#4 estimate/bound values are 0.095-in./ 0.107-in. when the two outlying values are included. Without the outliers, the values are instead 0.074-in./ 0.081-in. The outlying values have considerable impact, and they apparently come from some other physical condition that is not generating the smaller values. Fitting a statistical distribution across both the smaller values and the two outliers is therefore probably inappropriate. Instead the Plate \#2 and \#4 results without the outliers are probably the best statistical estimates of extreme values. But then it should be understood that around the circumference of the tank there are likely some other more extreme cases caused by whatever physical phenomenon caused these two outlying values. We certainly cannot fit a separate distribution to only two points to make some kind of worse case prediction for these more extreme cases. 
Riser Differences: Two inspections paths were completed down each of Risers 28 and 29. The use of two risers was based on initial studies of the first multi-riser-inspected Tank 241-AY-101 (in 2005). In that case, statistically significant riser differences were indicated, so it was determined that either multiple risers should be used in subsequent UT tank inspections, or if only a single riser were used, an extra uncertainty factor should be incorporated to account for such riser variability.

However, the resulting 2007, 2008, and now 2009 two-riser UT inspections of several tanks have tended to indicate that riser differences are not nearly as significant as originally thought. Discussion of inspection reduction to three or four paths down a single riser has been held, but for now the preference is to maintain the two-riser inspections. For the current Tank 241-AW-101 UT inspection, only modest differences between risers are indicated.

Old versus New Inspection Comparison: Approximately the same Tank 241-AW-101 wall areas were inspected both in the previous 2001 inspection and in the current 2009 inspection. This was the case for two inspection paths in Riser 28, so about 70 pairs of old and new UT image results could be compared. One elevation in path 1 was omitted since considerable wall thinning was indicated in the older inspection at that elevation, but it could not be found again in the new inspection after considerable effort. Since this one location generated a very large wall thickness gain from the old to new inspection, it was omitted from summary analyses.

For Tank 241-AW-101measured wall thickness reductions from the old to new are less than have been observed for most tanks that have been twice inspected. They ran about 0.007 -in., that is, less than 0.001-in per year. 


\subsection{References}

Posakony, GJ and AF Pardini. 1998. Final Report - Ultrasonic Examination of Double-Shell Tank 241AN-107, PNNL-11971, Pacific Northwest National Laboratory, Richland, Washington.

AF Pardini to CE Jensen dated August 22, 2000, Letter Report on Performance Demonstration Test PDT, May 2000. Copy is on file in the PNNL DST Project Records.

GJ Posakony to CE Jensen dated October 5, 2001, Letter Purdy Performance Demonstration Test (PDT) Report. Copy on file in the PNNL DST Project Records.

Weier DR and KK Andersen. 2005. Estimation of Maximum Wall Thickness Loss of Five DSTs (AN-107, AP-102, AW-101, AZ-102, and SY-101), PNNL-15415, Pacific Northwest National Laboratory, Richland, Washington.

Weier, DR, KK Andersen, and HS Berman. 2005. Riser Difference Uncertainty Methodology Based on Tank AY-101 Wall Thickness Measurements with Application to Tank AN-107, PNNL-15182, Pacific Northwest National Laboratory, Richland, Washington.

Weier, DR and AF Pardini. 2007. Evaluation of UT Wall Thickness Measurements and Measurement Methodology PNNL-16828, Pacific Northwest National Laboratory, Richland, Washington.

AF Pardini to GP Duncan dated October 6, 2006, Letter Pintler Performance Demonstration Test (PDT) Report. Copy is on file in the PNNL DST Project Records.

Castleberry, JL. 2008, Task Plan for the Ultrasonic Inspection of Hanford Double-Shell Tanks FY 2009, RPP-PLAN-38332, Rev 2, CH2M HILL Hanford Group, Inc., Richland, Washington.

AF Pardini to CA Burke dated January 13, 2009, Letter Laura Sepich Performance Demonstration Test (PDT) Report. Copy is on file in the PNNL DST Project Records. 


\section{Distribution}

No. of

Copies

\section{Hanford Site}
J. L. Castleberry (1)
R3-26

6 Pacific Northwest National Laboratory
K. K. Anderson (1)
K6-08
S. L. Crawford (1)
K5-26
A. F. Pardini (1)
K5-26
G. J. Posakony (1)
K5-26
M. L. Watkins (1)
K5-26
D. R. Weier (1)
K6-08 